\title{
1. Financial stability in a globalised world
}

\subsection{SECURING FINANCIAL STABILITY: THE CONTRIBUTION OF ECONOMIC POLICY}

Speech at the New Year's Reception of Deutsches Aktieninstitut in

Brussels on Thursday, 27 January 2011

\subsubsection{Introduction}

\section{Ladies and gentlemen}

Thank you for inviting me to your New Year's reception here in Brussels - the capital of Europe. It is a pleasure for me to speak to you today. The turn of the year lends itself to looking back and reflecting on the past year as well as to looking ahead to the new year. In this spirit I will start my speech with an overview of the economy in 2010 and the outlook for 2011 before addressing the issues of financial market regulation and the current debt crisis. I consciously refrain from calling the current debt crisis "European" since the strong accumulation of public debt is far from being a purely European problem; however, being in Brussels, I will, of course, conclude with some remarks on the necessary measures in the euro area.

\subsubsection{The Economy in 2010 and 2011}

Economically, the year 2010 brought a turn for the better. The world economy picked up considerably and the German economy in particular made an unexpectedly strong recovery from the stresses and strains of the financial crisis. Growth expectations from the beginning of 2010 were clearly outperformed during the course of the year. With GDP growth at 3.6 per cent, Germany was able to make up a good portion of the 4.7 per cent slump of 2009. In the process, Germany profited significantly from the rapid recovery of the global economy and global trade. However, more recently, domestic demand - which had already been an important 
stabilising factor at the height of the crisis - has gained momentum as well. The resilience of the German economy during the crisis in the face of an extraordinarily severe negative shock is, not least, the reward of major reforms that were undertaken in the first half of the last decade. Particularly, the increased flexibility on the labour market helped Germany to come through the crisis in an acceptable shape, and not only stabilised private consumption but also allowed enterprises a smooth handling of the surprisingly vigorous increase in demand in the upturn.

However, not all countries of the euro area have weathered the crisis so successfully. Indeed, the spectrum of economic performance has been rather mixed. The euro area has seen heterogeneity in growth rates before, but now parts are reversed, as Germany currently occupies the role of growth motor in the euro area. These differences within the union should not be dismissed as purely cyclical: they are a consequence of the structural adaptation crisis affecting several countries of the periphery. When one considers the difficulties these countries are currently facing as well as the possible consequences for the euro area as a whole, it becomes evident that the outlook for 2011 and beyond depends on drawing the correct conclusions from the crisis and, from there, taking the right decisions. The expectation at the moment is that the global recovery will continue in 2011, albeit at a slower pace than in the past year. Under this assumption, the Bundesbank in its December Monthly Report forecast GDP in Germany to grow at a rate of 2 per cent in 2011 and 1.5 per cent the year after. This means that the pre-crisis level of production would be reached at the end of 2011, and production would be back to full capacity at about the same time. Indicators that have been released since then support the picture of an ongoing recovery and have even tended to surprise to the upside.

Developments on the capital markets during the past year were affected by the loss of confidence that emerged during the course of the debt crisis. The initial uncertainty of market participants about the economic course of major industrialised countries as well as the uncertainty about the capability of several states to service their huge accumulated debt manifested themselves in highly volatile stock prices. Even so, financing costs for enterprises were only moderately affected. Compared to their five-year average, they actually decreased. Stock market developments, however, were rather diverse among industrialised countries. While the Japanese Nikkei ended the year with a loss of 3 per cent, the American S\&P 500 and the German CDAX recorded increases of 13 per cent and 14 per cent respectively. Even their optimism only gained the upper hand during the course of the second half of the year - at the same time as the economic outlook brightened. 


\subsubsection{Financial Market Regulation}

The crisis has clearly demonstrated the need for stricter financial market regulation, especially as the financial sector was at the heart of the crisis. Safeguarding financial stability has therefore rightly been a top priority on the policy agenda. The G20 agenda and the summit in Seoul in November testify to the global dimension of the task of financial market regulation. A number of crucial reform measures designed to secure financial stability have already been approved or at least got underway in the past year. The increase in capital requirements in quantity and quality, commonly termed "Basel III", is the most prominent achievement. The tightened requirements comprise a significant increase in minimum capital requirements, which will be introduced in stages over a sufficiently long transition period from 2013 to 2015, and the introduction of an extra buffer, which will be phased in from 2016 to 2018. These measures are intended to enable financial institutions to better cope with possible losses themselves and thus lower the probability of an institution becoming insolvent - which can be viewed as a first line of defence.

Measures that target systemic risk comprise a second line of defence that will come into play if the first line is broken and an institution becomes insolvent. In this regard, the Financial Stability Board (FSB) currently develops strong regulatory and supervisory policies in the interests of financial stability. On a national level, Germany has recently passed a law on the restructuring of insolvent financial institutions. This is certainly a welcome step, although, as in other areas of regulation, national restructuring mechanisms will only be fully effective if they are mutually compatible, i.e. if the approach for their implementation is internationally coordinated. On an institutional level, the European Union recently established the European Systemic Risk Board (ESRB) - which began work last week - to conduct macroprudential analysis and monitoring that aims to detect systemic risks at an early stage.

Other measures to address systemic risk are currently being developed and will accompany us throughout 2011 as they require either further discussion or at least ratification. As systemic risk is a complex area, the issue requires a multi-faceted approach. This includes the question of how exactly to deal with institutions that are "too big to fail" or the improvement of corporate governance, e.g. via the implementation of the FSB's international compensation standards. Further topics discussed with regard to increasing the transparency of financial market operations are the mandatory registration of institutions that currently operate in the shadow banking system as well as the standardisation of contracts and 
handling of derivatives. Regulation of the core area of the crisis will keep this year's agenda busy.

\subsubsection{Public Debt Crisis}

However, in spite of all the progress that has been made with respect to economic recovery and regulatory reform, the year 2010 will be remembered most for the public debt crisis in the euro area which marked the beginning of the third phase of the crisis. During the course of the financial and economic crisis, many countries had accumulated a large amount of debt via guarantees or costly fiscal policy measures that had been implemented to prevent vital markets from collapsing during the financial and economic turmoil, in particular after the Lehman insolvency. However, this was the case in most member states, and so the reasons why only some of them suffered a serious loss of market participants' confidence in their capacity to bear the debt burden lie further in the past: in these countries, fiscal and economic policy omissions in the years before the crisis led to an accumulation of explicit or implicit liabilities in the state's budget and a significant loss of competitiveness. Consequently, the driving forces behind the increase in perceived sovereign risk were not speculative forces on the financial markets but poor fundamentals.

When the loss of confidence culminated for the first time in May, comprehensive support measures for Greece - where the situation was particularly dire - were taken to avoid risks for the stability of the euro area as a whole. Financial support was tied to a tough, closely monitored adjustment programme aimed at restoring the sustainability of public finances in Greece. In addition, a rescue scheme financed by the IMF, the European Union and its member states was set up to deal with future intensifications of the crisis. Again, financial support is granted only if a member state undergoes a tough adjustment programme that secures public solvency. This conditionality is crucial: financial support can buy some time, but confidence in the sustainability of public finances will only return if substantial structural improvements in the respective countries occur - be it in Greece or in Ireland, which called for support from the EFSF, EFSM and IMF in November after the fiscal burdens related to supporting its oversized financial sector became overwhelming.

For the financial system's future stability and effectiveness, it is indispensable to ensure that confidence in the stability of public finances remains intact. To achieve this, not only a credible consolidation of public finances is needed but also improvements in economic governance in EMU that ensure prudent fiscal policies in the medium to long run. 
Against this background, the current discussion about - and even calls for - euro bonds must be viewed critically. Euro bonds would render all euro-area countries jointly and severally liable, thereby eroding each state's own fiscal responsibility. The incentive for consolidating public finances would be reduced, along with the credibility of and confidence in the state's ability to service its debt - which is certainly the opposite of what is needed.

\subsubsection{Conclusion}

Ladies and gentlemen, although the financial sector has been at the heart of the crisis, the third phase of the current crisis, which emerged in 2010, clearly demonstrated the importance of sound economic and financial policy, as confidence in a state's solvency also plays a substantial role in securing financial stability. For the time being, the euro area has the necessary measures to deal with the debt crisis at its disposal. I hope that this speech has highlighted the clear necessity of:

- a swift and ambitious budgetary consolidation in order to restore confidence in public finances,

- strengthening the Stability and Growth Pact in order to prevent states from manoeuvring into destabilising situations that can cause a crisis,

- a surveillance and early warning mechanism in order to have the ability to take countermeasures at an early stage if necessary,

- a crisis resolution mechanism that permits the euro area to deal with a country in crisis without undermining the no-bail-out principle and hence the incentives for responsible, stability-oriented fiscal policies, and the necessity of

- implementing a national "debt brake" to keep budgets in balance once they are consolidated.

The crisis has painfully demonstrated several weaknesses in the regulatory system and imperfections in our economic and fiscal policies. If we manage to improve the regulatory framework for the financial system and maintain well-disciplined government budgets, we will be in a good position to ensure financial stability in the future. This is the important task we must address in 2011.

Ladies and gentlemen, Europe is more than just economy and currency. Based on its tradition, culture and diversity, Europe is currently on its way to a new unity. We are all called on to help achieve this goal. 
There are many problems lying ahead of us. However, with courage, openness and honesty we can overcome these problems.

I wish you personally health and happiness for 2011 and I wish Europe, in particular, continuing success. It is worth working for.

Thank you very much for your attention.

$* * *$

\subsection{RULES AND TOOLS FOR CAPTURING SYSTEMIC RISK}

Speech at SVP Global's European Symposium on Perspectives on the European Distressed and Credit Markets in London on Tuesday, 4 October 2011

\subsubsection{Introduction}

Ladies and gentlemen

This symposium could hardly be more topical. Following on from this morning's contributions on the subject "Perspectives of the European Distressed and Credit Markets", I'm very pleased to have the opportunity to look beyond the credit markets and add a new dimension to the debate, namely that of regulation.

The financial and economic crisis rocked the very foundations of the global financial system and ruthlessly exposed the weaknesses in international financial supervision. In areas where there are a large number of road accidents, the authorities put up additional safety barriers, bring in speed limits or divert the traffic. On top of that, each car has to have a regular MOT. After the major crash that was the financial crisis, many people fear that regulatory reform will lead to an unfettered spiral of regulation. I disagree.

As a central banker, I would assess the impact of this reform package by whether we succeed in strengthening the resilience of the financial system. Ideally, the result of this process should be enduring and should not trigger any negative side effects, e.g. on competition. But there is a long and arduous road ahead. And it will entail costs for the banking industry. 


\subsubsection{The International Reform Agenda: What Have We Already Achieved?}

As an example of what we've already achieved, take the key points of the reform framework already adopted at international level: "Basel III", a far-reaching new global regulatory standard for bank capital adequacy and liquidity that was endorsed by the G20 at the end of 2010. Its objective, in brief, is to better equip banks for weathering future stress situations. The European Commission recently published a legislative proposal to translate the Basel III rules into EU law, which will affect over 8,000 banks. The Commission cited the IMF's loss estimates in its justification for this move. According to these estimates, crisis-related losses between 2007 and 2010 incurred by European banks alone were close to $€ 1$ trillion, or 8 per cent of EU GDP. ${ }^{1}$ Given this situation, we must not postpone the global implementation of Basel III; that would send out the wrong message. The Bundesbank welcomes the fact that Europe is playing a pioneering role in this area. The other G20 countries would be wise to avoid delays to or departures from the agreed Basel III implementation plan. In the interests of stability and competitiveness, ensuring that the Basel III rules come into force at the same time in all countries is just as vital as ensuring that they are implemented consistently at a global level.

In Europe, Basel III will apply to all credit institutions. Going back to the traffic analogy, all road users have to follow the highway code. The fact that another cornerstone of the reform agenda affects the large, systemically important financial institutions, or SIFIs, is therefore very important. They are the heavy goods vehicles - or even the super trucks - of the banking world; their size means that any accident they are involved in can cause gridlock on the roads. These SIFIs will have to obey stricter rules in future; one of the most important is that SIFIs will have to meet higher capital requirements than all other market participants. Some say that the regulatory reforms are forcing small banks to pay for the mistakes of the big banks. I disagree.

Many countries felt impelled to rescue some of these institutions with huge sums of taxpayers' money in order to avoid a systemic collapse. The problem of banks that are "too big to fail" and the moral hazard that this entails are to be remedied by establishing a specific supervisory framework for SIFIs. We should not forget that, just as cars primarily serve to transport people, the financial sector also has to serve the real economy. 
In July 2011 both the Basel Committee on Banking Supervision and the Financial Stability Board, or FSB, published a consultative document $^{2}$ which is an important step forward. The member states have agreed on a methodology for assessing the systemic importance of banks. In addition, special capital surcharges above the minimum capital requirements will be imposed on SIFIs. The more systemically important a bank is, the higher its SIFI capital surcharge will be. After evaluating the more than 40 commentaries to the consultative document it is clear now that the Basel Committee has done a very good job. Aside from a few adjustments and updates to the underlying data, which are already underway, the document is ready to be submitted to the G20 for approval at their summit this November.

The agenda for financial reform also regards a consistent implementation and surveillance of international standards as crucial to its success. ${ }^{3}$ FSB peer reviews are one means of achieving this. FSB members are to ensure that standards are implemented as strictly and consistently as possible following the principle "leading by example", ideally triggering a "race to the top".

One example of this kind of peer review is the remuneration standards. No one, not even the managers themselves, would dispute that misaligned remuneration systems for bank managers at least played a role in worsening the financial crisis. ${ }^{4}$ The G20 countries therefore adopted the FSB Principles for Sound Compensation Practices as early as September 2009 and, on this basis, specific implementation standards..$^{5}$ The Basel Committee has since incorporated the disclosure requirements specified in these standards into Pillar $3 .^{6}$ Germany was one of the first countries to implement the standards. The Regulation Governing Remuneration at Institutions, or Instituts-Vergütungsverordnung, came into force in Germany on 13 October 2010. This regulation takes account of both the international regulations and the subsequent EU provisions.

\subsubsection{What Progress Have We Made on ...}

\subsubsection{1 ... restructuring and resolution regimes for SIFIs?}

However, the international supervisory community still has much to do in the field of restructuring and resolution procedures for SIFIs. In a free market economy, we cannot and should not ever fully rule out the possibility of a specific financial institution collapsing. The insolvency procedures in individual countries have during the crisis proved to be insufficient - particularly for cross-border institutions. We must make it possible for SIFIs to undergo an orderly exit from the market without the use of taxpayers' money. Only credible resolution mechanisms can 
eliminate the market's rescue expectations - which means that having systemic importance must not be tantamount to being "too big to fail".

The more than 60 sometimes opposing commentaries in the FSB's public consultation ${ }^{7}$ on this issue have been carefully reviewed. The resulting "Key Attributes of Effective Resolution Regimes for Financial Institutions" will very likely be ready for endorsement by the G20 leaders in Cannes. Yet, the G20 countries must take account of the fact that the European Commission is currently working on a legislative proposal $^{8}$ on the same issue. In my view, we need to strive for international consistency between the G20- and the European framework.

Germany was quick off the mark in creating possibilities for winding up SIFIs. The Restructuring Act, or Restrukturierungsgesetz, which recently came into force in Germany, provides for all banks - regardless of their size - to be either restructured or wound up in an orderly procedure. In addition, the whole of the banking sector has to pay a bank levy which feeds into a Restructuring Fund so that the sector shares in the costs of overcoming future financial crises. It is estimated that the bank levy will channel around $€ 1$ billion per year into the Restructuring Fund, and the levy rate to be paid by each institution depends on its systemic importance - an aspect which I expressly welcome.

However, it is vital that we do not overburden financial institutions. I am therefore unenthusiastic about the plans to introduce a financial transaction tax. Much as I get the moral arguments for such a tax, setting the wrong incentives often means that the harm caused in practice outweighs the intended benefits - particularly when measures are not introduced internationally, which encourages business to migrate. We need to have a level playing field across the globe, especially within the EU.

\subsubsection{2 ... the shadow banking system?}

Ladies and gentlemen, how would a traffic authority react if there was a sudden spate of accidents involving vehicles that weren't - and still aren't - obliged to have an MOT purely because they aren't technically defined as cars? This is more or less what happened with the shadow banking system in the financial sector. First, I would like to stress that bank-like transactions outside of the banking sector should not be regarded as a bad thing per se. There can be advantages to certain activities being carried out by specialist enterprises rather than banks. The shadow banking system should not be considered the "villain of the piece", and I would not wish to support this standpoint.

The crux of the matter is to ensure that financial supervisors have sufficient information to promptly identify risks to financial stability 
originating from the shadow banking system. Containing risks emanating from the shadow banking system might well require regulatory changes. In particular, we need to avoid regulatory arbitrage at all costs, since we can expect activities and risks to be shifted away from the banking system in response to stricter bank regulation. I would therefore like to stress my support for greater transparency. Of course, I'm aware that reporting obligations engender costs. But, as every economist knows, there's no such thing as a free lunch. And I believe that the objective of financial stability justifies the costs that such obligations entail. The relevant authorities should therefore be entitled to impose reporting obligations on market participants - and this means all players that could be a source of systemic risk.

So which participants are we talking about here? The FSB defines the shadow banking system as "credit intermediation involving entities and activities outside the regular banking system". These can be non-bank entities, such as special purpose vehicles or money market funds. Hedge funds can also constitute links in a chain of intermediation outside the banking sector - after all, they collect funds and invest them in bonds and other credit instruments, including derivatives. But the FSB's definition of the shadow banking system isn't confined to participants; it also includes activities, such as securitisation.

Work towards addressing the issue of shadow banking is progressing well; this autumn, the FSB will submit recommendations to the G20 in a report focusing primarily on closing gaps and loopholes in transparency and regulation; these recommendations will have to be fleshed out next year. Again, I would like to stress that the oversight and possible subsequent regulation of the shadow banking system is primarily about the systemic risk that can arise in the shadow banking system.

\subsubsection{What Still Needs to Be Done?}

There is another lesson to be learned from the financial crisis: the pre-crisis supervisory approach of focusing mainly on individual institutions proved insufficient. It has to go hand in hand with macroprudential oversight, which aims to identify systemic risk and regulatory loopholes at an early stage so that countermeasures can be taken swiftly. To achieve this, we need, in particular, to improve the underlying information and data - as the situation in the shadow banking system illustrates.

In keeping with the international standards that are currently being elaborated, Germany's governing coalition proposed expanding the macroprudential oversight of the German financial system at its central 
bank. I understand that work is underway to draw up legislation based on this proposal - a development which I very much support.

Central banks are especially suited to the macroprudential aspects of financial supervision because they already have a duty to maintain a constant overview of market developments. As I've already mentioned, central banks are also aware of the side effects of regulatory initiatives. For example, central bank experts analysed the macroeconomic impact of the transition to Basel III in detail before it was adopted. ${ }^{9}$ An extended study on the implications of the planned SIFI capital surcharges provisionally concluded that they can be expected to have only a relatively small negative impact on economic growth beyond the planned implementation period.

In my view, it is generally important to look beyond the traditional confines of supervision when addressing these issues. This applies, for example, to the question of how recent international regulatory initiatives are affecting the refinancing conditions of domestic banks. It is not only the credit rating agencies' assessments which suggest that factors specific to individual institutions - such as their capital, balance sheet structure and business models - are the primary influence on banks' individual financing costs. Such factors tend to outweigh the effects not only of the macroeconomic setting, for example, but also of the costs caused by regulation. All in all, the large number of regulatory proposals, as well as their complexity and the rather unfinished nature of some initiatives, make it difficult to assess the overall picture. Ultimately, however, the competitive situation and bank-specific factors are likely to be the decisive factors affecting banks' refinancing conditions.

\subsubsection{Closing Remarks}

Ladies and gentlemen

Central banks and financial supervisory authorities face a difficult balancing act. On the one hand, in view of the objective of safeguarding stability, the institutional and regulatory framework has to be tightened and harmonised internationally. On the other, the new rules must not overburden market participants, and the effects of regulation, including its impact on competition, must be evaluated from a macro perspective.

However, the supervisory rules can only set the framework in which financial transactions take place. Market participants themselves must do their part to strengthen the financial system - by improving risk management, for example. 
I would propose that we central bankers and financial supervisors work through our agenda item by item and you, as representatives of large institutional investors, work through the tasks that you have to address. Since we drive on the same roads, so to speak, I look forward to continuing this dialogue with you. A good dialogue is the best way of avoiding any more collisions in future.

$* * *$

\subsection{COULD LESS BE MORE? THE ROLE OF FINANCE FOR THE ECONOMY}

Dinner speech delivered at the SAFE Conference on Regulating

Financial Markets in Frankfurt am Main on 30 May 2016

\subsubsection{Introduction}

Dear Mr Kick,

Ladies and gentlemen

Given that my speech is standing between you and the next course of our dinner, I will endeavour to be brief.

One colloquial definition of insanity is doing the same thing, over and over again, but expecting different results. ${ }^{10}$ By that standard, how sound is current financial regulation?

Looking at the many new topics of financial regulation on the agenda of this conference, it would appear that the response to the crisis has been quite sound. Your contributions and this conference in general are, in my view, very valuable in helping to understand why financial regulation needs to be strong and how it can work for the economy and our society.

And since you will be debating the details of these issues all day long, I will not go into the specifics of financial regulation.

Instead, I will discuss a remaining fundamental problem of financial policymaking - one where our current policies might fit the definition of insanity I quoted earlier. It relates to the question of how much finance we need for solving our current economic problems.

For over three decades before the crisis, the simple answer was "more is better". This mindset led us into the crisis, the consequences of which we are still witnessing today. To keep relying on more finance seems questionable.

The core problem, I believe, is one of mindset. I am talking about the idea that more credit and financial activity lead directly to economic 
growth. According to this plain idea, leverage and liquidity in banks lead to more lending, which in turn fuels investment, which then leads to more growth and economic development. In that spirit, some are, again, arguing that what the economy needs is less regulation and more lending.

I refer to this ideology as a "finance-led growth strategy". I am convinced that we must overcome these intuitively appealing ideas and their ideological siblings. In that spirit, tonight I will talk about our current economic challenges and the role that finance, on the one hand, and financial regulation, on the other, can play in underpinning sustainable economic development.

\subsubsection{Less and More in the Current Economy}

After the financial crisis, financial regulation has been hailed as a saviour of the economy. Yet the current state of the world economy and that of most advanced national economies are eroding this standing. In the face of populist pressures, simple political solutions that hold out the promise of jobs and participation in growth are being sought. Finance offers an imaginary panacea for this situation.

This situation is familiar from the pre-2008 period. It seems to be back on the rise, as global economic growth continues its sluggish trajectory of recent years. Fittingly, the IMF reported in April "Too Slow for Too Long". ${ }^{11}$ Moreover, the Fund expects growth to remain stubbornly stagnant. These growth problems seem to be based on fundamental economic challenges, all of immense magnitude: secular stagnation, be it driven by weak demand or weak supply; debt overhang; and demographic change.

Policies that do not look beyond the end of the election cycle are not the right way to address these types of challenges. Which is probably why the success of policy responses seeking to put output levels and growth back on track was only short-lived. Growth has been slowing in most advanced countries. So what now?

In the past, a popular response to sluggish growth was finance-led growth policy. But there are a couple of problems with that strategy which make it an unhealthy policy choice. The recent financial crisis offered yet another impressive example. However, too much finance leads not only to financial turmoil but also to economic growth being stifled by mountains of debt.

The overblown financial system and the extreme leveraging have left the world economy with a severe debt overhang, a mountain of debt. It was this excessive credit creation which paved the way for the financial crisis. During the crisis itself, it was plain to see that leverage needed to 
be lowered, especially in the financial sector. But precious little headway has been made in this regard, leaving us with an unstable financial system. $^{12}$

What's worse, the tectonic movements of these debt mountains have serious repercussions on the stability of the financial system. Doubts about the sustainability of the mountains of credit increase uncertainty about the economy in general and the financial sector in particular. Non-performing loans and unsustainable business models - which in many cases continue to build on the assumption that the pre-crisis environment will return - are still a drag on the resilience of the financial system.

Thus, while finance-led growth might be intuitively appealing, pursuing it once again would seem to fit our definition of insanity above.

\subsubsection{How Much is Enough? More Finance is Not a Panacea}

Nevertheless, policymakers are looking for solutions. Unfortunately, some still think that more finance is a sound way to ignite investment and development. Such a finance-led growth policy emerged as the dominant political strategy in the 1980s. That meant that financial deregulation was high on the agenda to foster financial development. And theory appeared to support this intuition, with studies showing that financial development corresponded strongly with economic growth. ${ }^{13}$

But, while finance seemed to be conducive to economic growth in the early stages, it also had serious negative repercussions for the economy. We learned the hard way that more finance is not a panacea! For two reasons: first, more credit and finance tend to lead to more frequent and more severe financial crises. ${ }^{14}$ Excessive credit creation increases the fragility of the financial system and the likelihood of financial crises. And the bigger the mountain of debt, the more severe post-crisis recessions tend to be. ${ }^{15}$

Moreover, financial turmoil is not the sole possible outcome of excessive debt. The second reason why more finance is not a panacea is that leverage seems to hamper economic growth once it exceeds GDP levels of around 90 to 100 per cent. Recent evidence reveals that there is indeed such a thing as too much finance. ${ }^{16}$ Financial depth starts having a negative effect on output growth once credit to the private sector reaches 100 per cent of GDP. Most advanced countries exceeded this level prior to the financial crisis - and continue to do so.

Recent studies found even lower thresholds at which financial deepening unleashes negative effects. In a Bank for International Settlements working paper, Cecchetti and Kharroubi found that the effects of credit 
on GDP growth turn negative once corporate debt exceeds 90 per cent or household debt 85 per cent - of GDP. ${ }^{17}$ The OECD's report on finance and inclusive growth last year found that the effects of private leverage on GDP growth turn negative once total private credit - household and corporate credit combined - exceeds 90 per cent.

For sure, there is no exact science to determine the appropriate level of leverage, but two crucial insights can be derived: first, there is such a thing as too much debt; second, current levels in most advanced and emerging economies exceed these levels. Together, these insights provide much better guidance for prudent policy and regulatory strategy than the finance-led growth agenda.

Thus, the diagnosis for advanced economies like the EU and the US is that increasing credit and financial activity is beneficial, but only up to a point. This point has been exceeded in most developed economies.

\subsubsection{Better Finance? More Quality, Please}

What's the takeaway from all this? It's that more finance is not the solution to our current problems. Sticking to the simple "more finance, more growth" trajectory is not sustainable. That would run the risk of focusing on what is currently our most pressing problem - lifting growth expectations - at the expense of our long-term - and fundamental - goal of achieving a stable financial system that serves the real economy. ${ }^{18}$ And by doing that, we would also sacrifice sustainable growth.

But, at the same time, excessive limits on financial intermediation would certainly undermine economic development.

Thus - as you all know - there is no simple, linear positive or negative relationship between finance and growth. And that is because there is a problem with the simple indicator that is typically used to assess the effects of financial deepening on economic development - that is, private credit to GDP. It's a crude measure which is incapable of measuring the quality and efficiency of a financial system - but that's what further development of an already advanced economy is about.

The problem with the current simple measure mirrors the problem with the political reality: a simple measure enables researchers to build great data sets and publish papers. Likewise, a finance-led growth strategy enables policymakers to create a simple political narrative and win support for a campaign or a specific policy action. The scientific and the political problem are of the same nature: complexity and detail simply aren't sexy.

Until the crisis, it was very, indeed, very sexy to claim that more finance meant more development. That truth was simple; it was clear; it was sexy. 
But it turned into an ugly sham. To find the new truth appealing, we need to embrace the complexity of the quality of finance and the subtle, indirect roles it plays for the economy. In other words, we need to accept the fact that the role of the financial sector in real economic development seems to lie in the quality of financial intermediation. And the importance of quality increases as an economy becomes more advanced.

The quality of finance can be found in the five mechanisms through which it serves the economy. Payment services reduce transaction costs; the pooling of savings helps to overcome investment indivisibilities; the large-scale organisation of screening and monitoring investments and loans reduces costs and increases overall investment; the reduction of liquidity risk enables long-term investment; portfolio diversification helps to spread out cross-sectional and inter-temporal risk.

None of these functions contributes directly to growth. Instead, all of these functions are support functions for economic development. Payment services, for example, are an important backbone of a monetary economy. The same goes for collecting and pooling savings, and, of course, the screening of investments. Yet, none of these functions in and of itself generates economic development - they merely facilitate it. This means that finance can enhance growth sustainably only by supporting real economic development.

So what do we take away from this? First, the economic value of intra-financial market transactions should be viewed with some scepticism. Second, the intermediation function - in particular to enterprises and to investment projects - is a crucial component of high-quality finance. Third, private credit is a double-edged sword: too much of it poses a hazard to financial stability and sustainable economic development.

In sum, in pursuing economic development, we should focus less on the cheap credit channel, and more on finding answers to two important questions: what kinds of investment are important for fostering economic and social progress? And how can the financial sector enhance the quality of its intermediation? The first question is for politicians and the public to discuss. The second requires the sector, researchers and also supervisors to come up with answers.

\subsubsection{Conclusion}

Ladies and gentlemen

For over three decades, the finance-led growth agenda hid the dangers of an uncontrolled financial system. This had serious negative repercussions for the economy. More finance is not a panacea: beyond sustainable 
levels, more credit and financial activity may lead to more frequent and more severe financial crises. And, moreover, without the event of a financial crisis, they seem to hamper economic growth once they exceed around 100 per cent of GDP.

We must not lapse back into bad old habits when finalising, implementing and enforcing the reforms aimed at restoring financial stability.

Moreover, some deeper challenges remain to be addressed: we need to understand how secular stagnation and debt overhang trends affect the economy, and which structural reforms are necessary. And, we need to understand how the financial sector can contribute effectively to the economy: the actual mechanisms through which financial intermediation can serve the real economy of advanced nations.

The bottom line is: what advanced economies need is not more finance, but better finance.

In that sense let me quote Antoine de Saint Exupéry, author of The Little Prince, who said that "perfection is attained not when there is nothing more to add, but when there is nothing more to remove". That wisdom could serve financial policymakers well, but it should not keep you any longer from continuing to enjoy a delightful dinner!

$$
* * *
$$

\subsection{MORE PAINKILLERS, PLEASE? WHY MORE FINANCE IS THE WRONG MEDICINE FOR OUR GROWTH PROBLEM}

Keynote remarks delivered at the Harvard Law School Symposium on Building the Financial System of the 21st Century: An Agenda for Europe and the US in Armonk, New York on 8 April 2016

\subsubsection{Introduction}

Dear Professor Scott, Dear ladies and gentlemen

2016 marks the 30th anniversary of the Program on International Financial Systems. That's about the age when young people begin to realise that smoking, drinking and working late hours won't leave their physique unscathed. Bad habits, happily ignored in younger years, catch up with them eventually. Some of us probably know what I am talking about. 
You could say that today's global economy has reached a similar point in its life. But it would be 38 today, having turned 30 back in 2008 when the financial crisis was raging. At that time, the global economy did realise that excess was detrimental to its long-term health. Now the world economy is eight years older - but is it also eight years wiser? In other words, have we cut back enough on our bad habits to thrive for another four or five decades? Or are we still leading a life of excess that will prove costly for tomorrow's financial health?

In my remarks today, I will argue that we have not yet done enough to adapt. For the global economy to become healthy and prosperous again and to stay that way - we need to adapt our policy habits. We have to move towards a more sustainable mix: fewer painkillers, less wine, more healing and greater abstinence.

\subsubsection{Stricken by Two Illnesses at Once}

Our subject, the world economy, is still struggling to adapt to the new realities of being "thirtysomething". It is stricken by two illnesses simultaneously.

The first is the result of the excessive lifestyle it led before the crisis. I'm referring to the overblown financial system and the extreme leveraging, which created a lasting liability in the shape of mountains of debt. It was this excessive leveraging which paved the way to the financial crisis. During the crisis itself, it was plain to see that leverage levels needed to be lowered, especially in the financial sector. But precious little headway has been made in this regard, leaving us with an unstable financial system. $^{19}$

The second ailment is that global economic growth has been stubbornly stagnant over the past seven years. ${ }^{20}$ Most policy responses to the crisis have sought to put output levels and growth back on track. Yet growth has been stuck in the doldrums in most advanced countries.

Thus, the global economy has been stricken by both stagnating growth and excessive levels of debt. These twin illnesses are very difficult to treat - especially so given that it is not entirely clear what exactly is behind the growth problem. ${ }^{21}$ Is it the unhealthy lifestyle of excessive finance, or is it another, more fundamental condition? Or could it be a more complex complaint in which stifling debt and low growth fuel each other in a vicious circle? 


\subsubsection{Financial Painkillers Aren't the Cure}

How are we supposed to treat these twin illnesses? Finance-led growth emerged as the dominant political strategy in the 1980s. That meant financial deregulation was high on the agenda to foster financial development, and monetary policy was used to counter financial turmoil.

In fact, monetary policy created a high degree of stability during the spell known as the "Great Moderation", which ran from the 1980s until 2007. This episode was characterised by gratifyingly low volatility in growth and inflation rates. That outcome can still be regarded as a good thing. And many attribute it, at least in part, to systematic monetary policymaking by central banks. This, however, came at a price. Monetary expansion drove liquidity levels higher, which in turn facilitated balance sheet expansion and excessive risk-taking. ${ }^{22}$

In the words of Ben Bernanke, "for the most part, financial stability did not figure prominently in monetary policy discussions during [the Great Moderation]." 23

Given this experience, a doctor treating a patient with these symptoms would stop prescribing painkillers. But as it turned out, the monetary "medication" actually started to be expanded in 2008. First via ultra-low interest rates, then through quantitative easing, followed, more recently, by even more monetary measures aimed at kick-starting inflation and the economy.

The liquidity provided stabilised the financial system, but it also inflated asset prices. ${ }^{24}$ The aftermath of the expansionary monetary policymaking before the crisis should serve as a reminder not to make the same mistake twice. Providing an endless flow of liquidity as a kind of painkiller does nothing to tackle the root cause of the economic challenges we are facing.

The second painkiller frequently administered to support financial development in the pre-crisis era was deregulation and a "light touch" in regulation and supervision. The idea behind this approach was that lenience would fuel increased investment. Unfortunately, it inflated the credit bubble.

Solid regulation and responsible supervision is the key to limiting future bubbles. Yes, we've already achieved a great deal since the crisis Basel III and TLAC at the global level; Dodd-Frank in the US; the banking union in the euro area. And some are saying we've already gone too far. The evidence, however, tells a different story: it is higher standards that strengthen credit intermediation and economic development. That's something worth remembering in the face of what are, intuitively, compelling claims about capital costs. These claims have been 
discredited by the experience gained during the crisis and by empirical evidence. $^{25}$

In sum, these policies did not constitute a sustainable lifestyle, nor did they deliver a systematic cure. Rather, they turned out to be painkillers. So the big question I'm asking myself is this: should we carry on treating the symptoms by taking more and more painkillers - or should we look for a fundamental change of lifestyle that might cure the underlying problems?

\subsubsection{Finance is No Panacea for Growth}

Put differently, do we need to treat the global economy with more monetary and financial stimulus? And, more fundamentally, do we need more finance to fix our economy?

For over three decades, the simple answer was "the more, the better". And scientific evidence supported this intuition. Studies showed that financial development corresponded strongly with economic growth. ${ }^{26}$ Politically, there was a clear preference for finance-led growth. Thus, deregulation was high on the agenda.

I won't remind you where all this led. We just need to remember the tremendous costs for banks and for society at large that followed the burst of the last credit bubble. ${ }^{27}$

Moreover, recent scientific evidence based on historical data reveals that there is indeed such a thing as too much finance. ${ }^{28}$ Financial depth starts having a negative effect on output growth when credit to the private sector reaches 100 per cent of GDP. Most advanced countries far exceeded this level prior to the financial crisis - and continue to do so.

Thus, the diagnosis for advanced economies like the EU and the US is that increasing financial intermediation is beneficial, but only up to a point. This point has been exceeded in most developed economies.

\subsubsection{What's the Right Medicine? Fewer Painkillers, a Better Cure}

What's the takeaway from all this? It's that more finance is not the solution to our current problems.

Sticking to the simple "more finance, more growth" trajectory isn't a sustainable solution. That would run the risk of focusing on what is currently our most pressing problem - lifting growth expectations - at the expense of our long-term - and fundamental - goal of achieving a stable financial system. And by doing that, we would also sacrifice sustainable growth. 
Most doctors would probably agree that a sophisticated course of treatment aimed at the patient's long-term well-being is better than a box of painkillers every week. But ask them what exactly they would prescribe, and the result will probably be rather like asking several economists for macroeconomic policy advice. You might end up with more treatment plans than you have doctors - or patients for that matter.

What we need is less, and better, finance - finance that serves the real economy and sustainable development. How do we achieve that? There are several angles to that question, but the ones I would like to emphasise are financial regulation and supervision, and monetary policy.

As I said earlier, providing a flow of liquidity as a monetary painkiller does nothing to tackle the root causes of the economic challenges we are facing. In the absence of economic progress on the structural front, monetary easing is not the key to a sustainable economy. It does, however, affect financial stability, given that it can fuel bubbles. Therefore, we need to look for an exit strategy. It is important for central banks to think hard about how they intend to achieve an exit as soon as economic conditions make it viable to do so.

From a more general angle, integrating financial stability considerations into monetary policy while maintaining the primacy of the price stability goal will be a key challenge for the future. I welcome the fact that central banks are moving in that direction.

Rock-solid regulation and responsible supervision is likewise indispensable for a stable financial system. Over and above the progress we have made since the crisis erupted, there are three more steps we need to take. First, we must credibly implement the agreed reforms - for example, the new bail-in instruments need to be credible so that politicians do not pre-empt the bail-in during times of crisis. Zombie banks should not be kept alive for political reasons. Uncertainty over the bail-in instruments will only exacerbate market uncertainty.

Second, supervision must be steadfast. Either banks are capable of managing their risks adequately, or supervisors must force them to do so - or, ultimately, they must take disciplinary measures. As such, it is up to a supervisor to increase an individual institution's capital requirements, if need be. At the same time, however, we must be careful that risky activities do not move to unregulated areas.

Finally, we must not discontinue our reform efforts prematurely. We need to put an end to the privileged treatment of sovereign exposures. We must regulate shadow banking. And we must finalise Basel III in a sound manner. Yes, there has been a commitment to not raise capital requirements significantly on average, as the Basel Committee and the G20 have clarified. But several German banks, for example, have already lifted 
their regulatory equity by more than 100 per cent between December 2010 and June 2015 - that's an increase from 58 billion to 118 billion euros. So we have already achieved a substantial increase in capital. But make no mistake: high-risk portfolios will end up with higher requirements. Moreover, a pledge to not significantly increase capital requirements certainly doesn't mean that requirements will fall back to their low pre-crisis levels.

The bottom line is this: we must not lapse back into bad old habits when we're finalising, implementing and enforcing the reforms aimed at restoring financial stability. Financial intermediation is important for our advanced economies. But if it's not or insufficiently regulated, it can do more harm than good. That should be borne in mind in each and every decision we take.

But talking about rules and their enforcement is one thing - they will only lead to better finance if banks and investors change their behaviour accordingly. Banks, especially European ones, have to adapt their business models. They need to set themselves sustainable profit targets which do not undermine ethical behaviour.

Without a doubt, such financial policies need to be complemented by fundamental economic policy reforms. But I'm certain that sound financial and monetary policy will be a cornerstone of a stable financial system that serves the development of the real economy over the long term.

\subsubsection{Conclusion}

\section{Esteemed colleagues}

We are facing two challenges simultaneously: to reanimate economic growth, and to build a sustainable financial system that is fit for the $21 \mathrm{st}$ century.

I am convinced that our policies need to set their sights on a long-term solution - a lasting cure, if you will, not an endless supply of painkillers. We should not turn a blind eye to the short-term challenges we face, of course. But what we must do is refrain from solutions that encourage excessive indebtedness. Finance will be an important ingredient in the cure for growth - but it will need to be of a better quality, not a greater quantity.

And now that I have preached abstinence, let us enjoy a delightful lunch! 


\subsection{UNDER PRESSURE: IS CONSOLIDATION THE SOLUTION FOR EUROPE'S BANKING SECTOR?} Speech delivered at the Conference "Doing $M \& A$ deals around the world”, Frankfurt am Main on 13 October 2016

\subsubsection{Introduction}

Ladies and gentlemen

About a week ago, the Nobel Prize in Medicine was awarded for work that is of indirect interest to the banking industry. Japan's Yoshinori Oshumi was honoured for exploring how human cells not only break down but also recycle cell trash that results, for example, from fighting diseases. Oshumi found that when this process, called autophagy, is disturbed, for example through ageing, this has serious repercussions on our health.

I think it is fair to say that this sort of mechanism was truly needed after the financial crisis revealed the damaging cell material within banks.

Eight years later, the question is whether the organisms of banks were capable of, and successful in, disposing of or recycling financial waste. Today, I will examine this question from a European angle. And I will also ask whether mergers \& acquisitions may well be one of the healing mechanisms of the European banking system.

\subsubsection{In Bad Shape? The Status Quo of Europe's Banks}

In the last few months, concerns about European banks spun out of control. While there was no panic, sometimes the media discussion made us almost feel as if there was.

Now, let's take a sober and realistic look at the facts. Over the course of this year, European banking stocks had to weather strong headwinds. While the overall European stock market, as represented by the Euro Stoxx 50 index, remained more or less unchanged, the Euro Stoxx Banks index dropped by more than 30 per cent. At the same time, volatility of the bank stocks remains high, although that seems to be heavily related to post-Brexit jitters.

Such market movements suggest some sort of doomsday scenario. Is that justified?

Clearly not. Current concerns about the European banking sector are overstated. Yes, the sector is not yet ready to be successful in the new post-crisis environment. And market sentiment reflects just that. But - 
and that's where exaggeration comes in - the sharp movements do not take into consideration that the solvency of the sector in Europe is not in doubt.

In other words, while Europe's banks still struggle to come up with long-term strategies to succeed in the new, different and truly challenging economic environment, in the short to medium term they would pass any health check - as the recent stress test by the European Banking Association confirmed.

But banks also show traits and habits that can, in the long run, result in serious health issues - unless a change of lifestyle can be achieved.

Let's consider the health facts. EU banks have strengthened their capital positions - even if non-performing loans remain a problem for some institutes: the aggregate tier 1 capital ratio of the banks in the euro area today stands at around 15 per cent. This exceeds pre-crisis levels in early 2008 by six percentage points. Another sign of good vitality and higher resilience is the improved ratio of common equity to total assets. Before the crisis, European banks held around 3.6 per cent of unweighted common equity; today, the average stands at 5.5 per cent.

Banks also broadly meet the new health standards of sufficient liquidity - to be prepared for times of market distress.

And the euro area's new bank supervisor, the Single Supervisory Mechanism, has contributed to more rigorous supervision and to stronger banks.

So for the time being, the European banking sector is nowhere near the brink of collapse. The reform efforts of policymakers and bankers alike have led to substantial progress - even if important reforms, like ending the sovereign-bank nexus, remain to be finished.

However, being healthy is one thing. Being in outstanding shape, being prepared for whatever challenges the future may throw at you, is another. To reach that level of health, banks still have a lot to do.

At present, efficiency at euro-area banks is too low, and many institutes still struggle with achieving a steady stream of sustainable profits with a minimum of volatility - although both, efficiency and profitability, do vary across individual countries and financial institutions. Profitability is not a goal in itself, but a means towards an end - and this end is the stability of a bank and its capacity to meet regulatory capital requirements. That's why supervisors are concerned about falling profitability. Efficiency, in turn, is a means towards the end of profitability - where increased cost-efficiency improves the return.

To be in really good shape for the challenges that lie ahead, banks in the euro area must work on their operational efficiency and need to adapt 
their income sources. This is true for many, if not most, financial institutions.

So, the condition of the banking sector is healthy in general, but it clearly could be better. This is problematic, as banks face a truly demanding future, one that holds several large-scale tasks.

Seeing as this speech stands between you and a wine-tasting, I will touch only briefly on each of these challenges.

The first lies in demographic change. The workforce is set to decline, while the number of non-working persons will grow. This will most likely be a burden on investment and on prospects for growth - which will both weigh heavily on banks' business. At the same time, customer cohorts will change substantially, forcing banks to adapt to new realities.

This all the more given the second challenge: digitalisation. Even though it's a long time since the digital revolution back in 2002, when humanity began storing more information in digital than in analogue format, the challenges of digitalisation to the banking sector seem to be everywhere. That is because digital applications are increasingly becoming mass phenomena in our everyday lives. This changes consumer demand and rearranges the value chain of financial intermediation. Banks need to adapt to keep up with customers and to hold on to attractive parts of the new financial value chain. So far, they have fallen behind some of their new, agile fintech competitors.

Perhaps the biggest medium-term challenge is the ultra-low interest rates. They weigh heavily on banks with interest-focused business models. The difficulty in passing negative central bank rates on to private customers leads to deposits being a drag on income. This presents problems for many banks. Small and medium-sized banks used to be praised for their stable business models that relied on taking deposits and earning higher interest margins through lending on capital markets. In an ultra-low-interest-rate environment this virtue becomes a challenge. And this environment is here to stay. Fundamental economic factors as well as central bank guidance indicate that low rates will persist for quite some time.

Finally, there is regulation. Many complain that regulation has become tougher. But I would argue that to criticise this is to question putting a lock on the drinks cabinet after someone in the family is hospitalised for overindulging. Tougher rules and more stringent supervision are not only necessary: they were long overdue. Complaining about their negative implications is to confuse cause and effect. The light-touch approach before the crisis was simply wrong. We are correcting that mistake now. But of course, to get into shape to successfully comply with these new rules is a demanding task. 
So, if we take a panoramic picture of the sector in Europe, what does it look like? Well, first of all, we see how the landscape has been cleaned up and dangerous areas secured. The European banking sector has made progress in improving both its solvency and its governance.

Yet, when we zoom into the picture, we see that the landscape is still dotted with contaminated spots.

Obviously, the reform progress is not over. A politician would probably stop now - thereby dodging the question on everyone's mind: what on earth does that mean?

Unfortunately, I have too much time left before your wine-tasting to stop just now.

\subsubsection{What to Do?}

What to do, then, to complete the reforms in the European banking sector? What should banks do? What should policymakers do?

For one thing - many, if not most, institutions must retool their business models. Until the financial crisis of 2008, the credit bubble allowed banks to inflate their income to unsustainable levels. This led them to build up capacities which, from the perspective of the real economy, were not fully needed.

Moreover, bubble-driven profits spared them from making their organisations lean and efficient. A study recently found for the US financial market that productivity gains in the financial sector from 1900 onwards were mostly concentrated in the area of secondary trading - while the productivity of primary market activities stagnated. ${ }^{29}$

In other words, banks need to fundamentally rethink their business models. Their goal should be to achieve, over the long run, a steady stream of sustainable profits with a minimum of volatility. For this, banks need to compete with fintech companies for customers with different demand patterns on the one hand, and open up new sources of income on the other hand. At the same time, they need to increase their operational efficiency considerably.

These changes to business models and operational efficiency are likely to bring about further cuts in the sector. We have seen this trend in Europe for some years now. Moreover, recent data and news releases on banks' plans to cut resources and reshape strategies indicate that this trend is ongoing. Thus, the sector is on a path towards a size and structure that will be sustainable in terms of the real economy's needs.

Yet to be clear, this can take many forms. We should not reduce this debate to a simple "we need fewer small banks" - more market players tend to be good for a functioning market. We should keep that in mind. 
There is no need - or mandate - for supervisors to interfere with these market forces. What we can and should do is to finalise the reform progress that began in 2008 , and to do so soon. And we will make sure that banks are put under close supervisory scrutiny.

\subsubsection{What Role for Bank Mergers \& Acquisitions?}

So far, I have answered the question as to what banks and policymakers should do.

That leads to the question - certainly in this room, at least: what role can mergers \& acquisitions play?

In the last few weeks, some have argued in public debate that competition in the banking sector is too high, which, in turn, results in low profitability of banks. Quite often this was then linked to the number of banks being too high. But as I have pointed out in the past, the number of businesses in a market is not a problem per $\mathrm{se}^{30}$

Nevertheless, I agree at least in part with the conclusion that mergers $\&$ acquisitions might be appropriate for some institutions.

And, as I outlined earlier, we have seen that adjustment in the euro area has already progressed in terms of the number of banks, employees, branches and balance sheet volumes. Thus, the question that arises is: how much more room is there for viable mergers \& acquisitions?

Before I answer this question, let's look at how successful banks were in the past when merging.

Generally speaking, when the businesses of two organisations are combined, you would expect higher cost-efficiency from economies of scale on the one hand and income synergies from cross-selling and complementary business lines on the other.

What we see in Europe, and also in Germany, is that on average the potential is less than that typically hoped for. The track record for mergers \& acquisitions in the banking sector is mediocre. ${ }^{31}$ On average, we see that banks were only modestly capable of achieving the desired cost reductions and higher profitability.

That, of course, does not mean that mergers are bad per se, but rather that it depends on the merits of each individual case. Are the institutions a good match? Are gains in operational efficiency possible? Will the increased size even result in less efficiency due to governance problems?

Successful mergers or acquisitions depend on whether synergies are viable. Ultimately, it's about careful decision-making with the long-term strategy in mind - but that also requires time for a painstaking, extensive analysis of whether the expected synergies and efficiencies are actually realisable with the two particular organisations concerned. 
Beyond analysis and efficiency, mergers or acquisitions is about people. If you forge incompatible cultures into one company, this is unlikely to generate synergies and economies of scale. Rather, it will lead to governance problems.

But consolidation can be fruitful, when banks find the right partners. Successful cases show that regional or business line compatibility provide a great source of synergies.

Selected acquisitions and sales of business lines can be a good instrument to strengthen a solid and focused business model. Again, careful analysis of the viability of synergies and efficiency improvements are a precondition for any such transaction.

One aspect strikes me as being very important. Merging ailing institutes with healthy ones is certainly no panacea. Certainly not in the eyes of bank supervisors. It may even entail risks for the healthy party of the merger. While mathematically two minuses make a plus, this is not at all the case with mergers. Moreover, creating further institutes that are too big to fail is certainly not an attractive option that would be accepted by supervisors.

Likewise, mergers \& acquisitions cannot absolve banks from dealing with the economic challenges I discussed earlier. Whether merged or not, becoming more efficient and profitable is an inescapable challenge for many institutes.

Essentially, mergers \& acquisitions may very well be a part of and support the banking sector's adjustment process, but it cannot be the main carrier of it. It can help where healthy institutions see the possibility to create synergies in a new environment, but it cannot, and should not, solve problems.

This implies that careful management decisions are key. And management, in turn, will rely on the astute advice of professional mergers \& acquisitions specialists.

\subsubsection{Conclusion}

Ladies and gentlemen

Europe's banking sector is healthy. But when the market sneezes, expect some banks to catch a cold. If we want to prevent unjustified contagion, then we need first to stay calm. We should take the time to consider the facts instead of piling on what is clearly exaggerated sentiment.

And yet we live in challenging economic times. To do business successfully and sustainably in this environment is an enormous task. 
Many banks are facing problems created by demographic change, digitalisation, ultra-low interest rates and enhanced banking regulation; and many have begun to address their efficiency and profitability problems.

But clearly, they are not yet up for a marathon with a good finishing time. There remains a lot to be done.

Reorienting business models and optimising organisational efficiency will be one part of the fitness regime. Another will be structural reorganisation in the sector. Mergers \& acquisitions will continue to play an important role here, too. But only the link-up of healthy players is likely to lead to stronger teams - although, even this cannot be taken for granted. Putting weak athletes together will certainly not lead to high performance.

I now look forward to a fruitful discussion ... and, of course, our wine-tasting.

Thank you very much for your attention.

$* * *$

\subsection{BANKING SECTOR IN UNCERTAIN TIMES: A CHALLENGE FOR WHOM?}

Keynote speech at the British Bankers Association Annual

International Banking Conference, London on Thursday, 20 October 2016

\subsubsection{Introduction}

Dear Chair, ladies and gentlemen

We are facing a surplus of pressing issues at the moment, each so important and complex that I could easily devote an entire speech to every one of them. Unfortunately, I cannot do that because my time is limited. But that is not actually a problem, because with so many different matters at hand, one can easily get lost in the details. Therefore, before we start discussing the current issues in greater depth, I would first like to take a step back and look at the bigger picture.

That is, I would not only like to put the challenges we are facing into perspective, but also reflect on the role I see for the stakeholders; i.e. for banks, regulators and supervisors as well as politicians. 


\subsubsection{Challenging Times for the Banking Sector}

If we look at how the European banking sector has developed since the financial crisis, there has clearly been quite some improvement. Compared to 2008, European banks have strengthened their tier 1 capital position by 6 percentage points to 15 per cent on average. Their improved resilience is also reflected in the leverage ratio. Before the financial crisis, European banks held around 3.6 per cent of unweighted common equity; today, the average is 5.5 per cent. Besides boosting their solvency, banks have also worked to enhance their liquidity buffers.

Yet over the course of the past year, European bank stocks have come under significant pressure. While the overall European stock market - as represented by the Euro Stoxx 50 - has more or less held steady, the Euro Stoxx Banks index has dropped by more than 30 per cent. Bank stock price volatility has soared, and CDS quotes suggest that confidence has recently declined in the creditworthiness of many listed European banks. So something is obviously worrying investors.

Complex issues can rarely be pinned on just one root cause. Indeed, banks in the UK and in the rest of Europe are being pounded by multiple headwinds. Let me briefly pick three of them.

First, we are currently seeing significant structural changes in the market environment. Two developments are decisive here. On the one hand, digitalisation is rapidly transforming the banking business. At the same time, banks and the economy face a prolonged period of very low interest rates. While net interest income hasn't been affected much so far, the pressure on margins is likely to mount over the medium term.

Second, banks operate in a still relatively new regulatory environment. And rules based on the Basel III regime are currently being finalised and phased in. The need to adapt to, and comply with, the new requirements is imposing costs on the banks and causing some headaches among bank managers. And the uncertainty about the final Basel III rules is rising, given that the last meeting of the Basel Committee is approaching at the end of November.

Third, to the surprise of most market participants and probably politicians as well, a majority of the UK citizens voted in favour of leaving the European Union. Many observers are concerned about the consequences of this process. And while many contributions to this debate are rather speculative at a time when negotiations haven't even started, there are indeed many complex problems to be solved and tough decisions to be made over the coming months and years. Nobody knows that better than you. 
Allow me just one short remark: interconnectedness between the UK and EU is significant in terms of both the real economy and the financial markets. Rearranging these complex ties will be a demanding task.

Many eyes in the banking sector are on the issue of passporting from the UK into the EU, and, closely related to that, on the question of whether, and in what form, the UK will retain access to the single market. There is also the matter of whether the City of London will be stripped of the ability to clear euro-denominated OTC derivatives after the UK has exited the EU.

These are just two of the most prominent examples of the regulatory uncertainty that is bothering the financial sector in the wake of the referendum. Further questions, such as the free movement of labour, goods and services, affect the UK economy as a whole and with it all the clients of banks.

Taken together, these headwinds are placing a strain on the earnings prospects of banks. This is also reflected by the earnings-per-share forecasts for European banks, which have been in decline since the beginning of this year for almost all major institutions. Bearing this in mind, it's certainly no surprise that bank stocks have underperformed the rest of the economy.

To make matters worse, the bulk of the developments I have just outlined aren't short-term hiccups; they will continue to absorb everybody's attention for quite some time to come. And I expect them to radically change the banking sector. So if you were asking yourselves whether coming here today to discuss some of them is worth your time, I am certain you have made the right decision.

\subsubsection{A Challenge for Whom, Exactly?}

When you find yourself in a challenging situation, it is usually a good idea to put all possible solutions on the table. Sometimes, it can be useful to look for ways to circumvent the problem. And it's also worthwhile examining who or what might be responsible for the problem at hand. Another tempting, but rarely fruitful, response is to blame the whole sorry affair on external factors which only someone else can do anything about, and to then ask that someone to do something to make the problem go away.

Unfortunately, this is a response I have seen all too often in the debates on the situation of the European banking sector. And it can come in different shapes and forms: central banks being called upon to change their monetary policy because the current stance, it is claimed, is destroying earnings opportunities for banks; regulators being asked to 
revisit reforms because they're said to be driving up costs too strongly; and policymakers being asked to steer Brexit negotiations such that the financial sector doesn't suffer disadvantages during divorce proceedings.

Notwithstanding the important question of how much truth there is in the economic mechanisms thought to be behind these statements, they do convey a false impression of who exactly is responsible for what. Contrary to what such statements suggest, it is not the task of central bankers, regulators or policymakers to avert or resolve difficult situations for the banking sector. To put it bluntly, no one can expect a comfortable environment for the financial industry. Nor a certain level of interest rates. Nor a certain market environment. Nor a certain kind or degree of regulation.

Now please don't get me wrong. I know very well that the current challenges are a Herculean task for many banks. And I understand that banks are struggling with them.

And I also believe that banks can expect a lot from their supervisors, regulators and policymakers. Let me give you some examples.

With respect to structural changes in the market environment, banks can expect supervisors to closely monitor the introduction of new technologies and the entry of new competitors, and to ensure that the playing field remains level by assessing both technologies and financial institutions solely according to the risk they pose to financial stability.

Banks can also be confident that central banks are aware of the challenges posed by low interest rates. That being said, it should also be clear that safeguarding an institution's net interest income is not the objective of monetary policy.

As far as the perceived burden of regulation is concerned, banks can expect regulators and supervisors to listen to their arguments and continuously explore areas where they can do better. For example, one area where I see room for improvement is proportionality, that is, tailoring supervision and regulation to better fit differently sized banks.

As a proponent of a free market economy, I also agree with most industry representatives that we should not regulate more than necessary to achieve a stable and effective financial system. Furthermore, the regulation that exists should be as bearable as possible - as long as it remains as tough as necessary.

What we cannot do, though, is hold back on regulation simply because the sector is having a hard time. After all, taxpayers didn't have an easy ride with banks in the years that followed 2007, either. Improving regulation was and remains necessary to restore trust in the banking sector. And any costs that it might involve must be weighed against the benefits of a stable banking system. 
Lastly, with respect to the future relations between the UK and the EU, you can expect supervisors to work to preserve the cooperative culture between authorities on both sides of the Channel and to keep regulation synchronised as a way of maintaining a level playing field. A politically induced uneven playing field that is skewed to favour certain financial centres over others would inevitably prove counterproductive in the medium to long term, as that would open loopholes and opportunities for regulatory arbitrage. Furthermore, banks are right to insist that Brexit negotiations should not be dragged out for too long and that there should be as much planning security as possible.

What neither supervisors nor policymakers can promise is that Brexit will not affect the rules for banks, or leave the sector unscathed. On this score, it is often argued that if Brexit hampered the banking sector, it might impair the financing of the European economy. I don't share those fears. Brexit and its possible repercussions for the City of London are unlikely to be an issue for financial stability or the financing of the EU's real economy. The financial sector has proven to be flexible in the past, and I am in no doubt that it will adapt and come to terms with any changes the negotiations might bring.

\subsubsection{Importance and Boundaries of Politics}

Ladies and gentlemen, I have given you an impression of the role I see for supervisors and central banks. Of course, there is another party from the public sector that plays a role: politicians.

And the importance of politicians can't be overestimated when it comes to the future relations between the UK and the EU. How these turn out can only be determined by the elected representatives of the people.

But there are also areas where politicians have, for very good reasons, restricted their own influence. I am talking about the realm of monetary policy and, to some degree, banking and financial supervision. As Governor Carney put it: "The objectives are what are set by the politicians; the policies are done by technocrats."

Nevertheless, we have seen some criticism of central banks and their policies from politicians lately. This concerned, for example, the handling of Brexit as well as conducting monetary policy and setting interest rates more generally.

In light of this criticism, it may be time for a friendly reminder that central bank independence is not debatable. Experience shows that political influence over central banks always leads into disorder. At the end of the day, independent central banks best guarantee price stability. 
Calling central bank independence into question, even only implicitly, can confuse markets as well as the public about who is in charge when it comes to monetary policy and supervisory decisions.

In summary, politicians are well advised not to exert influence in the wrong place or with the wrong measures. In this context, I am also worried about some rather protectionist tones in recent economic and legal debates. Politicians as well as public authorities must resist any temptation to give preferential treatment to domestic companies and banks - or to exert excessively tough action on foreign businesses. As Barack Obama recently said: "A nation ringed by walls would only imprison itself."

\subsubsection{Conclusion}

Ladies and gentleman, over the past few minutes I offered you an overview of what I believe the banking sector can expect from supervisors, regulators and politicians - and what not. It turned out to be quite a long list.

If, as a bank representative, you were to ask me what I expect from banks in return, I would say just one thing: I expect you to take up the challenge.

In a market economy, coping with multiple challenges and an adverse business environment is the core responsibility of a business's management. No one else's.

At the beginning of my speech today, I spoke about an imminent and profound change in the banking sector. After the dust has settled, there will not only be winners. But if we honour the division of responsibility between banks, supervisors and policymakers, we can open up the path towards a banking sector that is both stable and profitable.

Of course, this is not to say that there shouldn't be communication or even cooperation among the parties involved - quite the contrary, in fact. That's why it's so important to have opportunities, like today's conference, to get together and discuss not just the challenges, but also the strategies needed to overcome them. I am looking forward to having this conversation with you now.

Thank you very much for your attention. 


\subsection{BANKS NAVIGATING UNCHARTED WATERS} Speech at the Instituto de Estudos de Política Econômica, Rio de Janeiro on Friday, 2 December 2016

\subsubsection{The World in Uncharted Territory}

Ladies and gentlemen

Do you remember where you were on the evening of November 8, 2016? It was a Tuesday, and judging by the headlines in literally every major newspaper in the world on the day after, the world was in a state of shock. The sentiment that dominated the greater part of media coverage of the US presidential election was also apparent in social media and in personal conversations probably everyone in this room had in the days that followed.

The outcome of the US election has caused a great deal of uncertainty. How will the change of government affect the foreign and security policy of the United States of America? What influence will it have on trade, regulatory and environmental issues? What will it mean for US relations with other regions, in particular Europe and Latin America?

As you know, the US presidential election was not the first vote that took markets and the public by surprise. In June this year, UK voters left Europe astonished as they voted to leave the European Union. Both decisions were taken in an already agitated situation in which the world is facing terrorism and tension over security in several parts of the world. On a different front, it is still fighting the after-effects of the worst financial and economic crisis since the Great Depression.

Looking ahead, we see more potential stumbling blocks. The Italian constitutional referendum will be held next Sunday and the French presidential election in about five months from now, just to name two of them.

All those past and future events have two things in common.

First, they actually change our world, or they have the potential to do so. Many expect this change in society, politics and economics to be for the worse. While we can try to predict how exactly the change will affect us, we have learned that such predictions are doomed to fail. In the end, we have to cope with a certain degree of uncertainty - and at the moment, there is plenty of it.

Second, these various events can tempt us to look for easy answers. Being confronted with multiple issues simultaneously, each complex 
enough in itself, can be overwhelming. The prevalence of oversimplification, polarisation and populism in recent political campaigns is a reflection of this desire for a simple solution.

\subsubsection{Parallels to the Financial World}

Ladies and gentlemen, I hope you are not wondering by now if you accidentally ended up in the wrong room, listening to a talk about contemporary history, political science or sociology.

Because what I have just described is also very relevant for my field of expertise - the banking and financial sector. It is my impression that, like the world as a whole, the financial world is currently going through its very own period of change and uncertainty, that it is struggling just as much to cope with it, and that we are just as prone to the lure of easy answers.

In this context, you may already have come across the term "the new normal of banking". It suggests that the sector has reached some kind of new equilibrium and that we have understood what it characterises. First of all, I doubt that this is true. And second, to be honest, whenever I hear this phrase I don't even know exactly what is meant by it.

Therefore, I want to dedicate the remainder of my remarks to an overview of what I believe to be the major developments in and challenges for the banking sector. I will also discuss possible answers to these challenges. Coming from Deutsche Bundesbank, I will of course be doing this from a European perspective. But in our discussion later on, I am eager to hear your views on, and to learn from your experiences in, the financial sector in Brazil and Latin America.

\subsubsection{Challenges for (European) Banks}

Let me start with a challenge I have already mentioned: the pending divorce of the UK and the EU. I have mentioned it because of its political impact. But as you know, it has strong implications for the financial sector as well and will continue to do so. Many eyes are on the question of whether, and in what form, the UK will retain access to the single market. In the financial realm, the related question is whether financial firms in the UK will continue to benefit from what we call "passporting". Currently, many international banks use London as a hub to conduct business within the European Economic Area. But depending on the deal that will be struck between the UK and the EU, passporting in its current form might end - and with it the possibility to enter the European market through the UK. Another open question is whether the City of London 
will still be in a position to clear euro-denominated swaps and other euro-denominated transactions once the UK has formally exited the EU.

These are just two of the most prominent examples of the regulatory uncertainty that is troubling the financial sector in the wake of the UK referendum. Further questions such as the free movement of labour, goods and services affect the UK economy as a whole and with it all the clients of banks.

Given that formal negotiations have not even started yet between the EU and the UK, there are still plenty of plausible scenarios for their future relations, and thus for the environment banks will have to operate in. This uncertainty surrounding Brexit will stay with the financial sector for some time to come, and there is no easy way around it.

Let's move on to the second issue, which concerns regulation more generally. Earlier this week, I was in Santiago de Chile to meet with my colleagues from the Basel Committee, where we discussed details for completing Basel III. The rules based on this regulatory regime are currently being finalised and phased in. Important aspects of the current negotiations are the revisions made to the level and the calculation of capital requirements.

The need to adapt to, and comply with, these new requirements is imposing costs on banks and causing headaches among bank managers. This holds for European financial institutions in particular. In comparison to Brazil, for example, the use of internal models for calculating risk-weighted assets and thus capital requirements is widespread in Europe. Consequently, any changes to this approach - as currently discussed - have much stronger implications for European banks than for their counterparts elsewhere.

It is therefore crucial that the final result of our current negotiations will be regionally balanced and does not undermine the risk-oriented approach of the Basel framework. The Committee was not able to reach such an agreement yet. We will continue our negotiations with the goal of ending regulatory uncertainty as soon as possible. And we will work towards finding a compromise before the Committee's oversight body the Group of Governors and Heads of Supervision - will meet in January.

In parallel with reforming Basel III, in Europe we have established the banking union with a whole new supervisory architecture at its core - the Single Supervisory Mechanism. This supervisory mechanism is still relatively new territory for banks, as it has just recently celebrated its second anniversary.

As you can see, the regulatory and supervisory world is changing significantly and rapidly for banks. Keeping up with these developments is a challenging task. 
On top of that, we are currently seeing significant structural changes in the market environment for banks. Two developments are decisive here.

On the one hand, digitalisation is rapidly transforming the banking business. While technology has always played a prominent role in banking, the speed and force of the current wave of digitalisation is unprecedented for European banks. Small fintech start-ups as well as major tech giants are forcing their way into the market, for example by providing instant payment services with a speed and convenience unmatched by the traditional services that banks have on offer. In parallel, technologies with the potential to disrupt individual business models are being honed and refined, and made ready for the market.

In contrast to some banks in Europe, most Brazilian banks are already well advanced in digitalising their business. Ironically, this is due to the fact that they mostly set up their IT later than their European counterparts. This observation is very much at the heart of the challenge posed by digitalisation: in the field of IT and digital services, it is not sufficient to put up a high upfront investment in order to ensure quality that will last for years. Instead, you need to do both: move early on and then continuously keep up with the pace of digital innovation. Only then can you ensure both - IT and cyber security as well as the quality necessary to satisfy an increasingly elusive customer base.

The impact of digitalisation on the financial world - and the world as a whole - cannot be overestimated. But there is a second structural challenge that is even more pressing for many financial institutions. I am, of course, talking about the prolonged period of very low interest rates.

The low-interest-rate environment is a prime candidate for the lure of the easy answer. And the seemingly easy answer is that low interest rates are the result of misguided monetary policy. But this answer reflects a common misperception as to the root causes of the low rates.

The downward trend in long-term nominal and real interest rates across the world has been visible since the 1990s. This trend accelerated after 2007 with the financial crisis. The macroeconomic literature currently discusses a number of structural causes as potential explanations. Without going into details on the research, there are indications that show that a slowdown in global growth together with shifts in savings and investment behaviour, partly driven by demographic change in industrial countries, have led to a fall in the price of capital. With the financial crisis and the recession that followed, the fall in the desired levels of investment together with expansionary monetary policy have pushed down rates even further. 
In summary, not only are the very low interest rates influenced by central banks: they also reflect an economic malaise in the global and in the euro-area economies.

Irrespective of their origin, the very low interest rates pose a serious challenge for profitability in the financial sector. This is particularly the case for banks whose business model depends heavily on net interest income. First of all, the margins derived from maturity transformation are declining because of the very flat yield curve. And second, deposit-based refinancing, which we have always regarded as highly desirable as a stable source of funding, even in crisis periods, becomes less attractive. This is because it is difficult to pass on negative rates to small private depositors in a very competitive market and when depositors always have the alternative of hording cash.

Despite the low rates, net interest income hasn't been affected much so far. But the pressure on margins is going to mount over the medium term as outstanding loans are repaid and replaced by lower-yielding ones.

A major risk associated with a low-interest-rate environment materialises when that spell comes to an end. In this scenario, pre-tax net income would probably suffer a short-term slump, especially if interest rates were to climb abruptly following a long period of low rates. In the short term, this would lead to present-value losses. More importantly, as banks are by their very nature engaged in the business of maturity transformation, a rise in interest rates will force them to roll over their liabilities at higher interest rates. But the yields on their assets will still reflect the low-rate environment.

Moreover, the longer banks have to cope with low interest rates, the more they are likely to take risky assets onto their books. We can observe that banks are extending the average maturity on the asset side, which is exposing them to more credit default and market risk.

At the same time, European banks are still holding significant amounts of non-performing loans in their books. For the euro area as a whole, the stock of NPLs amounts to roughly 9 per cent of euro-area GDP, more than double the level in 2009, and is only declining slowly. If we instead measure the amount of NPLs relative to total loans, we get the so-called NPL ratio. This ratio stands at 5.5 per cent on average for European banks. However, we can see a strong dispersion of NPL ratios across countries. The highest NPL ratios are present in those member states that were hit hardest by the economic crisis that followed the financial crisis after 2007.

The high stock of NPLs ties up operational capacity of the affected banks, it involves legal as well as administrative costs, and it weighs on 
the capacity of those banks to extend new loans to realise profits and to support economic recovery.

\subsubsection{How to Cope}

Ladies and gentleman, the financial world is clearly confronted with significant change and uncertainty. And many in the financial world perceive this to be a change for the worse.

There are no easy solutions. The Brexit negotiations will take time and uncertainty will be with us just as long. Turning back regulatory achievements to provide relief from a perceived burden is not an option. As for the challenges posed by digitalisation, sticking to business as usual will not suffice. The same is true for the low-interest-rate environment: hoping for relief from a change in monetary policy won't be enough.

Clearly, banks need to adapt, and indeed they have already begun. Any long-term strategy for profitable banking needs to be built on its value added for customers, business partners and society.

In times like these, supervisors need to be especially vigilant in monitoring financial institutions and ensuring that they do not take on excessive risks. What supervisors will not do is attempt to be management consultants for banks.

Difficult though the times may be, and however numerous and complex the problems may seem, it's important to keep a clear mind and a steady hand.

Having a holistic and encompassing understanding of the current challenges does not mean that there are broad encompassing solutions available. We will succeed only if we refrain from falling for sweeping answers that promise to solve all the issues at once. That's why it's so important to have institutes like the IEPE that enable us to get together and thoroughly discuss both the challenges and the strategies needed to overcome them. And I am looking forward to having this conversation with you now.

If we approach and tackle our current problems one by one, we will see that any change is manageable - both in the financial and in the real world.

Thank you for your attention. 


\subsection{HOW TO MANAGE FINANCIAL CRISIS FROM A SYSTEMIC VIEWPOINT}

Speech at the 40th Economics Conference of the Central Bank of the Republic of Austria "European Monetary Union - lessons from the debt crisis", Vienna on 10 May 2012

\subsubsection{The Gordian Knot}

In these times of debt crisis some observers have resorted to speaking of a "Gordian knot", implying that "cutting the knot" would put a quick and easy end to the problem. I must admit that this viewpoint leaves me surprised and slightly worried.

It reminds me of a story by the great novelist Manès Sperber: a figure in his writings is a boy, who was asked by the teacher: "What do you know about the Gordian knot?" The boy's answer is remarkable: "Nobody can solve the Gordian knot, including Alexander. But instead of admitting this, Alexander took the sword and cut the knot, what every stupid guy could have done. Henceforth, Alexander was called the Great." The teacher, who apparently admired historical heroes, was not amused: "Sit down; six", he said. Those times the marks ranged from "one" to "six", not from "AAA" to "D".

Another novelist, Erich Kästner, wrote in his essay "The Gordian knot: If I would have used my pocket knife to cut the knot of my shoestring my mother would have got angry." "You must not cut knots", she would have answered: "Shoestrings can be used again." Clearly, mothers have a better idea of how to deal with knots when they arise.

In my opinion, the moral of both these stories is similar to the lesson that can be learned from the current financial and sovereign debt crisis: there is no easy way to solve the crisis without tediously disentangling the knot, whether there is a sword or not. Cutting the knot is something different from solving it. And containing the crisis is something different from solving it.

\subsubsection{The Loops of the Knot: Systemic and Fundamental Elements of the Current Crisis}

Only a few terms have experienced such a surge in usage in recent years as the words "systemic" and "macroprudential". But what is the difference between a systemic and a non-systemic event?

If an event is non-systemic it can be treated in isolation. In the case of the debt crisis, the debt problems of countries can and should be treated 
as a series of individual problems and not as a systemic problem affecting the euro area as a whole.

Things are different in the case of a systemic event, mainly due to the effect of contagion loops between the different sovereigns, the loops between the public sector and the financial sector, the contagion loops between different financial intermediaries and ultimately the feedback loops between the financial sector and the real economy.

The degree of financial integration in the euro area is such that if some sovereigns are pushed into a bad equilibrium this affects other countries. The banking system can become fragile. What starts as a liquidity problem can easily turn into a solvency problem. Strong externalities are created, making it impossible to isolate the problem of one country from the rest of the euro area.

At the outset, the event might have originated locally, caused by local problems, in which case it might only be possible to solve it by addressing those root problems. In the meantime, however, we have seen how local problems can turn into a systemic problem.

For example, local problems in some countries arise from a low degree of competitiveness, unsustainable fiscal positions or a combination of both. The eventual solution is a gradual and steady improvement of their competitiveness and fiscal positions. There is no substitute for such an adjustment process at the local level. In the present situation, however, we may need additional instruments, for example firewalls or recapitalisation measures, to address the systemic component.

Turning to another example, the interest rates of some countries proved too low during the first decade of the euro, leading to house price booms and credit growth in those countries. These two factors have contributed to the recent crisis. Again, local problems turned into a systemic problem. Here, the solution is a balance sheet adjustment of banks and households. And again there is no getting round this tedious approach. The instruments to address the systemic component that are now available may assist this process.

At the end of last year we saw clear signs of a systemic financial crisis. The provision of liquidity for a period of three years, together with measures to strengthen fiscal discipline and to restructure Greek debts in an orderly fashion, has managed to mitigate the stress to some extent; at least for some period of time. Recently, tensions in the market have renewed due to doubts of the solidity of the fiscal positions of some countries. Moreover, market participants have realised that the loops of the knot between the public sector and the banking system in some countries have become tighter, not looser. This emphasises the need for fiscal consolidation; that is, disentangling the knot. 


\subsubsection{Firewalls: A "Sword" for Cutting the Knot?}

This characterisation of the systemic component determines the rationale for a firewall and its design. Simply by building confidence, a firewall can prevent or mitigate contagion without actually having to be triggered. If triggered, it can help to prevent a country's liquidity problem from turning into a solvency problem. Moreover, it can buy time and serve as a tool for commitment to implement necessary reforms.

No doubt: a large and effective firewall can reduce the likelihood of being triggered. However, the major issue here is the risk arising from simultaneity of payouts. The greater the simultaneity, the less credible a firewall can be, because it cannot cover the financing needs of all countries simultaneously.

Thus, a firewall is limited by the capabilities of the individual contributors. In a crisis characterised by having a systemic component with a high degree of market integration and loops between the public sector and the banking sector, the probability of coincident payouts seems to be high.

Proponents of a firewall to act as a "sword" for cutting the knot seem to ignore this fact. The challenge is considerably more complex. It requires a design that balances the confidence-building effects of an availability of sufficient funds where this is needed with the possibility that simultaneous payouts can overburden contributors.

Moreover, an appropriate design of firewalls has to take moral hazard considerations into account. In this context, moral hazard is a serious problem. As policies needed to generate a long-term solution are subject to complicated political processes, the political incentives to not follow through on those solutions can be strong. This would undermine what I consider to be the essential benefit of a credible firewall: its potential ability to encourage prudent economic policies.

To summarise, financing by means of firewalls is no substitute for restoring solvency - or to go back to my original metaphor - it is not an effective sword for cutting the knot. This can only be achieved through economic adjustments and structural reforms, in which case a firewall may well be helpful.

\subsubsection{Recapitalisation: Another "Sword" for Cutting the Knot?}

The loops that exist between the sovereign risks and the risks in the banking system in the current crisis make it necessary to address banking risks specifically. Capital buffers might offer an appropriate solution. The 
rationale for recapitalisation was outlined in the Bundesbank's most recent Financial Stability Review. I quote:

in times of systemic stress, markets cease to make broad based distinctions because [...] it is almost impossible ex ante to forecast the position of an individual bank. [...] Given the high degree of interconnectedness and the risk of contagion, this challenge demands not just an adequate capitalization of national banking systems but also convincing solutions that are coordinated across Europe.

In principle, adequate capital buffers strengthen the resilience of the financial sector, because they interrupt the sequential failure of institutions and mitigate contagion risks. They can reduce the procyclicality present in the system as they create room for manoeuvre before risky assets and credit supply have to be reduced in case a systemic event occurs.

In an ideal world these buffers are set up during a boom period; they are to be used when a crisis emerges, which is the idea behind countercyclical capital buffers. However, if the buffers are low relative to the risks that are building up when the event has already occurred, there is the risk of excess deleveraging and procyclicality. This is where public aid comes into play. This may assist the recapitalisation of the banking system thereby counterbalancing excessive deleveraging pressure.

As you know, this is the strategy followed by the European and national authorities, combined with some moral persuasion to abstain from excess deleveraging. And it looks like this strategy is going to be successful. At least this is what the capitalisation plans of banks indicate. Most of them intend to adjust their liability side to a large extent, not their asset side.

Of course, in some countries there is nevertheless some deleveraging pressure; but this is, or was, due to the refinancing needs of their banks and is not caused by the recapitalisation plan itself. On the contrary, if a loss in confidence is a major reason for the refinancing problems, restoring confidence through publicly assisted recapitalisation might be a key tool to mitigate excess deleveraging.

Moreover, deleveraging consists of both structural and cyclical components. It cannot easily be separated into "good" deleveraging which enforces the necessary adjustment of business models and "bad" deleveraging which implies a reduction of healthy business.

Again, publicly supported recapitalisation is not a sword for cutting the knot, but rather an instrument to assist necessary adjustment. 


\subsubsection{Disentangling the Knot: Addressing Systemic Risks by the ESRB}

The discussion so far has shown that in the modern-day financial system the loops of the knot are intertwined in complex, multidimensional ways. This calls for a coherent and systematic approach to addressing the problems. Since the beginning of 2011, with the European Systemic Risk Board, Europe has had a new macroprudential oversight body for analysing systemic risks with formal "warnings" and "recommendations" to be deployed as formal macroprudential instruments. The ESRB comprises all European and national supervisory authorities as well as central banks, with the latter playing a dominant role.

Given its institutional structure and the nature of its instruments, the comparative advantage of the ESRB lies not with crisis management. It lies less than ever with constructing "swords" for cutting the knot, but in crisis prevention and mitigation, that is, in disentangling the knot.

At an early stage, the ESRB can identify fundamental and local factors with the potential to prepare the ground for a systemic event. It can also recommend counteractive regulatory measures. This gives it the chance to address potentially systemic risks at an early point in the cycle. Once successfully implemented it can unburden itself, for example, of its monetary or fiscal policy tasks. This allows policymakers in those areas to concentrate on their own targets, leaving it to those responsible for macroprudential oversight to safeguard financial stability.

For example, if it is the case that low interest rates lead to excessive leverage or to excessive risk-taking or to house price bubbles in some countries in a monetary union, there is nothing that monetary policy can do about this. By contrast, once we have macroprudential instruments at our disposal we can use a leverage ratio or a loan to value ratio, just to mention two options. The ESRB has recognised the importance of having sufficient flexibility. In an open letter to EU authorities it states: "Macroprudential authorities at both Member State and Union level need discretion to require additional disclosures and to tighten temporarily a diverse range of (Pillar I) calibrations."

Establishing a macroprudential policy framework in a monetary union reminds me of a complicated balancing act. That is, first, to find the right balance between a sophisticated system which is fine-tuned to any marginal change in systemic risk and an approach based on easy-toimplement rules. The second challenge is to find enough flexibility when implementing instruments without endangering the level playing field. So far the discussion is not completed and requires also some practical experience. 


\subsubsection{Conclusion}

So what is the moral of my speech? Clearly, I have no sword to remedy the situation. And for those who wish they had such a sword, the idea of undoing knots may sound like "muddling through". But to my mind, this stony road of muddling through, this long-term disentangling of the knot, is vastly preferable to the alternative of cutting the knot. It means doing things the hard way and entails much future sacrifice and commitment. At the end of the day I have nothing to offer but "toil" and "sweat".

Nevertheless, thank you very much for your attention.

$* * *$

\subsection{FINANCIAL SYSTEMIC RISK: THE NATIONAL AND INTERNATIONAL DIMENSION OF MACROPRUDENTIAL POLICY}

Public lecture at the International Center for Monetary and Banking

Studies (ICMB), Geneva on 12 February 2013

\subsubsection{The Case for Macroprudential Policy}

Dear Professor Wyplosz,

Ladies and gentlemen!

Recently, The Economist reported that, more than a millennium ago, this very city was destroyed by a tsunami which came off of Lake Geneva. Today, we are coping with the fallout of a different storm: a financial one that took place in 2007 but has its roots in earlier years. Ever since, systemic risk and macroprudential policy are at the top of the agenda of policymakers, regulators and central bankers, and for good reason.

I appreciate very much having been invited today to share my thoughts on why macroprudential policy is of such vital importance. I will touch on its broader implications at both the national and the international level. Therefore, most of my comments are generally applicable, but allow me to voice some thoughts on the current debate in the European Union.

The financial crisis has made it clear that systemic risk with its implications for financial stability was not given enough attention in the past. We have learnt the painful lesson that we have to put the financial system on a sounder footing, and we need to draw the right conclusions from the global financial crisis. The costs of inaction have been high, and 
doing nothing is simply not an option. Thus, our approach to regulation and supervision has to adapt to this insight and take a more systemic view. In this regard, let me suggest that one could draw a somewhat simplifying analogy to nature.

In nature, species or populations have to adapt to their environment in order to survive. In an evolutionary system, continuous development is vital merely in order to maintain the fitness of an organism relative to the system with which it is co-evolving.

Similarly, the financial sector as well as regulation and supervision may be considered as a system that is evolving over time. Its different players are continuously interacting with one another and must adapt to change in order to succeed. In the same way as financial institutions respond to legal constraints, the regulator has to take their reactions into account and set the right incentives to safeguard financial stability.

All players in a functioning financial system need to respond to new developments so that a balance can be maintained. From this angle, the financial sector can be seen to have become more globalised, more complex and more integrated. You will agree that therefore regulation constantly has to adapt to keep up with its changing environment.

Adopting a systemic view is paramount. With this I mean it is of paramount importance to take due account of the external effects of individual actions and of their repercussions within the financial sector and, ultimately, of their implications for the real economy, sovereigns and taxpayers. In this sense, macroprudential policy provides a framework for thought and action, for deciding how much resilience we want and how much we are willing to pay for it.

\subsubsection{National Dimension: Goals and Interactions with Other Policy Areas}

But why do we need a distinct policy? Would it not be enough to take system-wide implications into account in other policy areas such as monetary and fiscal policy or microprudential supervision?

There are two main arguments why a specific macroprudential policy is called for and both of them I find important.

One is set out by Nobel laureate Jan Tinbergen in his contribution "On the Theory of Economic Policy": achieving a number of goals requires an equal number of instruments. For example, setting the interest rate is effective when targeting a specific goal such as inflation. However, using one instrument to try to achieve multiple goals inevitably impairs the effectiveness of that instrument. So even though the interest rate impacts on financial stability, it is likely to clash with the objective of ensuring 
price stability. Moreover, it may be too blunt to achieve this policy goal, especially in a monetary union when risks originate from regions or sectors whose economies are not developing in sync.

The second argument: each policy area only should have goals that are not mutually conflicting. Would it be wise to make the Transport Ministry responsible for environmental protection? Or would it not be more sensible to have an Environment Ministry in charge of it? Assigning potentially conflicting goals to different policy areas ensures that each policy area is committed to its task.

Therefore, an independent macroprudential policy safeguarding financial stability is needed and should be equipped with its own instruments. More precisely, there are two main objectives of macroprudential policy, which should be distinguished carefully.

First, it should provide a framework and rules that give the market participants appropriate incentives. This holds true in normal times but especially when crisis management measures have to be applied.

Second, macroprudential policy is about prevention. It puts in place instruments to keep systemic risk from building up over time. This can happen during times of exuberance when instruments have to be tightened. But it also can be necessary during downturns when previously accumulated capital or liquidity buffers can be released. Other instruments are designed to prevent spillover to other parts of the economic system.

In order to achieve these two objectives successfully, macroprudential policy has to take into account interactions with other policy areas. This is because different policy areas might reinforce or counteract each other. Coming back to my previous words, let the following situation serve as an example: while environmental policy is trying to reduce traffic pollution, at the same time transport policy is promoting enhanced mobility and infrastructure improvements by having new roads built.

The same issue about reinforcing and counteracting effects applies to the interaction between monetary policy and macroprudential policy.

In the short run, a potential conflict between the two policy areas cannot be ruled out. This might be the case if real and financial developments diverge, for example when monetary policy should be tightened but the financial system is stressed. Or it could happen when an economy is undergoing periods of high productivity growth, which reduces inflation but at the same time may trigger irrational exuberance in financial markets. This, for example, was the case during the dotcom bubble at the turn of the century.

However, once a longer-term perspective is taken, tensions tend to disappear. Over such a time horizon, price stability and financial stability 
are complementary. Monetary policy needs a functioning transmission process and a healthy financial system in order to be successful, while price stability is a key precondition for financial stability.

Similarly, there are interactions between macroprudential policy and fiscal policy. They are interrelated because banks hold a large quantity of their own government's debt in many countries. Unsustainable public finances have a direct impact on the rating of sovereign bonds and thus on banks' balance sheets. As a consequence, waning market confidence, losses and strained funding conditions can be detrimental to the resilience of the financial system as a whole.

Fiscal policy can also impact on financial stability through tax incentives. Just think of the role that tax incentives play in the overheating of real estate markets, for example by promoting owner-occupied housing through overly generous tax deductions for mortgage lending rates. Or think of the widespread preferential treatment of debt over equity. Thus, macroprudential objectives may sometimes conflict in the short run with political objectives pursued by means of tax policy.

Even so, by setting the right incentives, taxation also can be a useful tool for safeguarding financial stability. Some activities, such as excessive short-term funding, represent a systemic risk and could be curbed by an appropriate levy. This would make them more expensive and thus less attractive for market participants.

Finally, macro- and microprudential policy can crucially impact on one another. Both aim to enhance resilience and ensure stability. However, one focuses on single entities, while the other looks at the system as a whole. And even if the tools employed often work in the same direction, they may not always be perfectly aligned.

Microprudential regulation sometimes favours investment in certain "safe" asset classes. However, this may conflict with financial stability concerns as common exposure could involve systemic risk. Awareness of spillovers and feedback effects is a very important first step. It also fosters the understanding that both policies should complement each other. Achieving microprudential objectives depends on a stable financial system. Conversely, a stable financial system builds on sound individual institutions.

In my home country, Germany, a new institutional set-up for macroprudential policy takes these interactions between policy areas into account. A Financial Stability Committee has been established; it comprises representatives from the Bundesbank, the federal Financial Supervisory Authority and the German Finance Ministry. Together, they are in charge of designing consistent macroprudential policies. By involving different institutions, this set-up ensures a comprehensive point of view. 
Similarly, other countries will set up their own national macroprudential framework and take decisions regarding their financial system. Thus, measures will be adopted at the national level but will also have an impact across borders. Therefore, macroprudential policies will have to take spillovers into account. Equally, market participants must learn about the macroprudential policies of different jurisdictions. This thought leads me directly to my next topic: banking union and macroprudential policy.

\subsubsection{Banking Union and Macroprudential Policy}

In a financially integrated area such as the EU, spillover effects from one country to another are especially pronounced. Any national policy that affects financial stability might have an impact not only at home but across borders, too. This holds true not only for any measure taken but also for measures not taken.

Furthermore, the developments of the last years have dramatically shown the perils of the sovereign-banking nexus. The proposal for a banking union in the EU can be seen as a step towards better addressing spillover effects and disentangling sovereign and banking risks.

The banking union will start with a single banking supervisor. With a common set of rules on microprudential regulation, a European supervisor will be best placed to ensure a common supervisory practice. This is to avoid forbearance or a policy of "too little too late". Inaction can lead to severe problems in financial institutions and contagion in the financial system. Moreover, a European supervisor helps to preserve a level playing field, which is essential to the single market.

However, as envisaged by the banking union, a common resolution scheme should soon complement a single banking supervisor. First of all, it will ensure that owners and creditors bear the risk of their investment. A common resolution scheme would also avoid inconsistencies and frictions that could otherwise arise between a single supervisor and national resolution authorities. Ultimately, it could significantly improve the way in which we cope with failing internationally active banks. Their orderly recovery or resolution is a key element of financial stability and cross-border effects play a crucial part in it. A common resolution scheme will also help to reduce negative spillover from the banking sector to governments. Should public backstops be necessary to fund the resolution of banks governed by the Single Supervisory Mechanism, a burden-sharing agreement will have to be in place.

A banking union surely contributes to financial stability. But it is not a panacea. Current financial risks in national banking systems developed 
under national supervision. Thus, the ultimate responsibility is national. Any other solution would be a fiscal transfer and should be treated as such, including obtaining the obligatory democratic legitimacy.

Setting up a banking union and a single European supervisor also touches on institutional questions. Furthermore, it requires us to work out how the new set-up will relate to macroprudential policy.

Regarding the institutional framework, it must be ensured that the conferring of any supervisory powers on the ECB does not call into question the independence of monetary policy and the central bank's mandate for price stability. But I will not, at this point, go into further detail about the design of the banking union. Instead, I would like to expand briefly on the relationship between a banking union and macroprudential policy.

In contrast to the common set of rules of microprudential regulation, the essence of macroprudential policy is to detect, assess and respond flexibly to a build-up of systemic risk wherever and whenever it occurs. Even with a banking union, cyclical patterns in the euro area will vary to some extent. Under a single monetary policy, regionally differentiated macroprudential policies are vitally needed to combat systemic risk.

But who should be responsible for implementing macroprudential policies?

On the one hand, there are arguments for national authorities. Given that the macroeconomic costs of a systemic crisis are borne largely nationally, it seems reasonable to assign national authorities the responsibility to cope with the changing nature of systemic risk. Furthermore, a granular understanding of the national economy and the financial system is needed. National policies will involve implementing specific measures, such as the countercyclical capital buffer, sectoral risk weights or capital or liquidity surcharges.

On the other hand, national authorities may sometimes be biased towards inaction. Or they do not fully take into account spillover effects, whose potential costs have to be shared in a banking union. This might be addressed by assigning the power to tighten national macroprudential policies to the European level. Indeed, in December 2012, European finance ministers agreed to confer this power to the single banking supervisor.

At present, the European Union already has an independent body responsible for macroprudential oversight: the European Systemic Risk Board. Within its framework, there are established rules for the interplay between European and national authorities. This includes accountability on a "comply or explain" basis. As opposed to the Single Supervisory 
Mechanism, the ESRB comprises all 27 EU member states. It also is not confined to the banking sector but rather addresses the entire financial system.

The responsible parties now have to figure out how to fit the macroprudential aspects of the banking union and the ESRB together. While it is too early to know what the final set-up will look like, the ESRB will certainly not become obsolete. It plays, and will continue to play, an important role in coordinating policies.

\subsubsection{Concluding Remarks}

In conclusion, let me return to the analogy I used at the beginning of my speech. Macroprudential policy can be understood as a framework for responding to needs that have arisen because of the way the financial sector has developed. Thus, macroprudential policy seeks to restore the balance in the financial system populated by market participants, regulators and supervisors.

Unlike in evolution, the objective has been set. Nevertheless, to achieve the desired goals, interactions with other policy areas as well as cross-border spillovers still have to be taken into account. As a consequence, market participants themselves will have to adapt, to comply with new regulatory requirements and to develop their own responses to a changing environment.

Some responses might turn out to be unnecessary for a healthy economy. But former Fed Chairman Paul Volcker was taking things to extremes when he said, "The only useful banking innovation was the invention of the ATM." Other innovations, however, are beneficial to the development of our financial system, and those should be the ones that survive.

The potential failure of the financial system can come with a huge price tag for society. For this very reason, a stable system is essential. Macroprudential policy will have a key part to play in this, and national macroprudential responsibilities are about to be assigned in many countries. Appropriate instruments now need to be developed and implemented; we will have to "walk the talk". This will be a major challenge for some time to come.

Thank you very much for your attention to the topic which is close to my heart. 


\subsection{RESILIENT BANKS: ESSENTIAL BUILDING BLOCKS OF A STABLE FINANCIAL SYSTEM Speech at the 18th Annual Banking and Insurance Conference "Making finance work in a higher capital world", organized by Bank of America Merrill Lynch, London on 24 September 2013}

\subsubsection{Introduction}

\section{Ladies and gentlemen}

Many thanks for inviting me to this year's conference. It is a real pleasure for me to speak before you today because I spent many years of my career in the private sector. Today, however, I speak to you as a central banker and thus from a regulator's point of view.

From time to time banks and regulators are portrayed as opposing forces. To me, this seems a bit off the mark - not least because I know both sides rather well. In the end we all share the same objective: a stable financial system.

And a natural starting point from which to build a stable financial system is the individual bank. Banks are the elementary building blocks of the financial system and to ensure financial stability we need resilient banks.

\subsubsection{What Defines a Resilient Bank?}

But what is a resilient bank? To begin with, a resilient bank is able to withstand shocks. A resilient bank enjoys the confidence of investors and customers. Thus, it will receive funding - both wholesale and retail - at adequate prices even during periods of stress.

But how do investors and customers recognise a resilient bank? Is it like the famous giraffe: hard to describe but you know it when you see it? Well, there are certainly times when this is the case. Usually, however, resilient banks have specific characteristics that set them apart from other banks.

In my remarks today I would like to discuss three of these characteristics - three pillars on which resilient banks rest.

\subsubsection{Capital and liquidity buffers}

Capital and liquidity buffers should be regarded as the centre pillar. Capital provides a cushion to absorb losses during times of stress. And 
with the benefit of hindsight, it is now widely acknowledged that prior to the crisis banks' capital buffers were neither high nor solid enough.

The same is true for liquidity. Banks' role in financial intermediation makes them particularly vulnerable to liquidity risks. And a lack of liquidity can break a solvent bank's neck. After all, a liquidity squeeze was the defining element of the financial crisis in 2008.

In terms of strengthening individual banks' capital and liquidity buffers, we have come a long way. The Basel III rules require banks to hold more and better capital. These rules have since been transposed into European legislation. Once they are implemented, banks will be able to absorb bigger losses while remaining a going concern - they will be more resilient.

Although the implementation will be gradual, banks have already become eager to build up their capital buffers early on. In doing so, they are responding to increased market expectations. In Germany, for instance, the 12 major banks with an international focus increased their tier 1 capital ratios from 13.2 per cent to 15.3 per cent by mid- 2013 on a year-to-year basis.

However, some banks will still have to raise their capital or adjust their balance sheet positions accordingly.

Regarding the issue of liquidity, we have, for the first time ever, agreed on an international standard. I am sure that this new standard will increase banks' resilience to liquidity shocks, promote a more stable funding profile and enhance overall liquidity management. However, more analytical work needs to be done - not least because liquidity regulation is uncharted territory. Moreover, a lot of side effects and unintended consequences need to be fully thought through.

\subsubsection{Profitability}

The second pillar on which a resilient bank rests is profitability. Banks that are not profitable will lose the trust of their investors and customers, especially in times of stress. Also, they are not able to build up reserves, for instance by retaining earnings. This further weakens them in times of stress.

Prior to the crisis, many banks' ambition to increase shareholder value led to expectations of returns on equity of more than 20 per cent. Generating returns of that order may be profitable but not necessarily sustainable. But banks need business models that are both profitable and sustainable. I am fully aware, though, that this is easier said than done.

Just take a look at German banks. Like many of their international peers, German banks have been under pressure from a number of challenges for several years now - some crisis related, others structural. 
In addition, the German banking market is still highly dense and highly competitive.

For all these reasons, many banks still need to optimise their business models - for instance, by diversifying their funding sources or by giving up business units whose risks cannot be managed effectively. Those banks that cannot adapt swiftly enough to changing conditions should exit the market.

Now, when discussing the issue of profitability, it is often held that regulation increases banks' costs and reduces their earnings. It is certainly true that regulatory requirements do entail some costs for banks. However, I would take a more balanced view on the costs of regulation. Banks tend to overlook the costs of crises, as these are usually borne by taxpayers. Taking these costs into account puts the banks' criticism in perspective. At the social level regulation still generates a net benefit.

\subsubsection{Good governance}

Having said that, let us turn to the third pillar of a resilient bank. A resilient bank has a sound governance structure and is committed to high ethical standards. Investors and customers need confidence that banks are managed prudently.

These aspects have gained a lot of attention in the aftermath of recent scandals, such as the manipulation of LIBOR and similar financial benchmarks. These cases of misconduct spoil confidence in a twofold way.

Firstly, the trustworthiness of banks involved is impaired. And this has negative consequences for the banking sector as a whole. Banks will have to work hard in order to heal the wounds. Secondly, the reliability, robustness and representativeness of financial benchmarks have been called into question. Without doubt, the integrity and credibility of benchmark-setting processes are in urgent need of a general overhaul.

We all know: trust is gained only over a long period of time but may be shattered quickly. In a sense, trust is similar to Humpty Dumpty: it is very fragile and, once it has been shattered, all the king's horses and all the king's men will not be able to put it back together. In that vein, all efforts to strengthen banks' resilience can be undone instantly if banks cannot avoid severe cases of misconduct in future.

This also applies to banks' risk management capacities. On this issue, however, much progress has been made. The requirements for adequate internal control systems and appropriate governance structures have been tightened substantially.

Let me elaborate on this by referring to reforms of banks' compensation schemes. In the run-up to the crisis, asymmetries in compensation 
in terms of risk and reward led to short-termism and excessive risk-taking by some employees. Inadequate pay and reward systems contributed to large - and in some cases extreme - absolute levels of compensation. That in turn left firms with less capacity to absorb losses as risks materialised.

To safeguard financial stability, compensation schemes in the financial sector must be better aligned with the long-term performance of firms and with prudent risk-taking. International guidelines to this effect have been developed by the Financial Stability Board.

To date, the implementation of these guidelines is still seeing good progress. But much work still lies ahead for national authorities and banks. They have to ensure effective implementation of sound compensation policies that lead to more prudent risk-taking behaviour of employees. The strong compensation requirements that Europe has set in the legislative package on capital requirements are an important step in this direction.

But achieving lasting change in behaviour and culture will take time and stamina. Banks need to undertake further efforts to publicly disclose easy-to-understand and consistent data on their compensation structures that allow for comparisons across jurisdictions.

\subsubsection{Looking Beyond the Individual Bank}

To sum up the characteristics of resilient banks, we can state that they are well capitalised and have enough liquidity, that they have profitable and sustainable business models and that they are managed prudently. First and foremost, it is certainly the banks' responsibility to fulfil these criteria. It is the responsibility of regulators, however, to put in place a stable regulatory framework.

Nevertheless, in designing such a framework they have to look beyond the individual bank. Experience over recent years has shown that certain dynamics can jeopardise the entire financial system even though all single entities were believed to be sound: the whole is more than the sum of its parts.

Therefore, setting regulatory standards to increase the resilience of individual banks is necessary but by no means sufficient. Authorities have to broaden their perspective to cover the financial system as a whole. They have to take into account the problem of systemic risk.

Systemic risk can be created by cyclical or structural developments, such as exposure concentrations or externalities caused by the interconnectedness of financial institutions. 


\subsubsection{The "too big to fail" problem}

The first step in this regard is to acknowledge that even resilient banks can fail. And this might become a problem if the failing bank is very large and interconnected. In such a case it can drag other banks down with it and cause a systemic crisis. Consequently, we have to ensure that such systemically important financial institutions (or SIFIs) can fail without destabilising the whole financial system.

What we need are insolvency frameworks that are in tune with the interconnectedness and complexity of the financial sector. Major steps have already been taken in this regard at the international level. The Financial Stability Board has already presented key attributes of effective resolution regimes for financial institutions. These were endorsed by the G20 heads of state and government in November 2011.

Since then, work has been under way to transpose this new international standard into national law. A draft directive for the recovery and resolution of credit institutions has now been presented at the EU level. This proposal clearly sets forth the sequence of liability for failing financial institutions - shareholders and creditors are now first in line to bear losses, and rightly so.

\subsubsection{The bank-sovereign nexus}

Nevertheless, there is still another aspect of interconnectedness that has to be taken into account: the link between banks' balance sheets and public finances. The crisis has exposed a vicious circle in that connection.

If many banks run into financial difficulties at the same time, that can threaten the stability of the entire financial system. Governments then often have no option but to bail out these banks to prevent the system from collapsing. This costs a lot of money. Look at Ireland, for example: rescuing its banks raised the country's 2010 budget deficit to more than 30 per cent of GDP.

By the same token, if government finances run into difficulties, that causes problems for banks - firstly, because many banks have large government bond holdings and, secondly, because the general economic situation initially worsens when a government has to adjust its finances.

This feedback loop between banks and sovereigns has to be severed in order to promote financial stability. One measure would be to establish resolution regimes for banks as I have already discussed. Having them in place would shield the government from having to rescue banks with taxpayer money.

Another measure refers to capital requirements for banks, which I have also discussed. The objective is to ensure that banks' economic situation 
no longer depends on the state of public finances. We can only achieve this if we stop giving government debt preferential regulatory treatment over other loans or securities. Government debt should be backed with a level of capital which adequately reflects its risks. At the same time caps should be imposed on bank sovereign debt holdings.

And on a side note: appropriate capital rules and caps on lending to governments also have a disciplining effect on national fiscal and economic policy. Former IMF Chief Economist Kenneth Rogoff considers this effect to be stronger than that of stricter fiscal rules.

\subsubsection{Conclusion}

Ladies and gentlemen, resilient banks are the essential building block of financial stability. With a view to regulation we have come a long way since the recent crisis. We have reformed the regulatory framework in a way that will help to increase banks' resilience.

At the same time we have acknowledged the fact that we have to look beyond the individual bank if we want to safeguard financial stability. Thus, although we are on the right track, we should probably move a bit faster with regard to implementing the new rules and standards.

But what about the banks themselves? Have they finally understood their role in the recent crisis? Have they looked beyond their own losses and realised the burden they have put on society?

I have argued that we have to look beyond the individual bank to safeguard financial stability and what I was referring to was the systemic perspective. But we also have to look beyond the banks to capture the personal perspective. Eventually, it is the bankers' attitude and culture that are the most essential building blocks of financial stability. Here we still need a change. Bankers have to subscribe to the idea that the financial system is, in essence, a service provider for the real economy.

Thank you. 


\subsection{SHAKEN BUT NOT STIRRED? THE BANKING SYSTEM SEVEN YEARS AFTER THE CRISIS Speech at the Financial Markets Group Research Centre of the London School of Economics and Political Science, London on 29 October 2015}

\subsubsection{Introduction}

Dear Professor Goodhart,

Dear Charlie Bean,

Ladies and gentlemen

Thank you very much for inviting me to speak here today. It is a great honour to give a public lecture at the LSE and the Financial Markets Group Research Centre, which truly is one of the leading European centres for academic research into financial markets.

In my speech tonight I will outline the status quo in the banking sector and the most pressing challenges. "Shaken but not stirred" might be an accurate description of its present state, which still presents many challenges. In saying that, I am, of course, alluding to one of your country's most successful exports: the agent who not only solved the Cold War, but who has recently also begun to prevent wrongdoing on the financial markets - James Bond.

In the 2006 version of Casino Royale, for example, Bond's opponent, Le Chiffre, engages in insider trading and market manipulation. In anticipation of his terrorist plot to destroy a prototype aeroplane, he bets on the fall in the stocks of the aircraft manufacturer. Moreover, he engages in extreme leveraging: by financing the bet with money borrowed from African rebels, whom he has promised high returns on the 'invested' money. Of course, it is not the supervisory authority, but Her Majesty's agent James Bond who prevents the attack, resulting in the collapse of Le Chiffre's fraudulent plan.

Insider trading, market manipulation, extreme leveraging, terrorism financing - you can imagine how daunting a task like financial supervision is in a world without James Bond.

Seriously, though, besides the aspects I have just mentioned, there were even more problems with banks and the financial markets before the financial crisis. 


\subsubsection{Reconstructing the Financial Infrastructure after a Perfect Storm}

Seven years ago, we were in the midst of a perfect storm unleashed by the financial crisis that had the Lehman Brothers insolvency as its focal point. The events and revelations that ensued put the global economy into recession and discredited the banking sector. This led to an overwhelming demand to bring the state back in: for robust regulation of financial markets, and of banks in particular, so that the financial sector would serve the real economy and society, not the other way around.

I guess many, if not most, observers back then would have expected such a task to have been completed seven years later. Nevertheless, I stand here today to convince you that we have not yet arrived at that point. Rather, we need to continue the reconstruction of the banking sector. We need to finalise reforms with the aim of ensuring a stable banking sector that, at the same time, serves the real economy and achieves sustainable profitability - in that exact order. This remains a broader challenge for society as a whole - one not only for banks, markets and supervisors, but also the general public, academia and the media.

The financial crisis and the subsequent recession revealed to us why this is such an overwhelming challenge: the financial system, and banks in particular, provide an essential infrastructure function for modern economies. Their stable functioning is a public good. The negative externalities of actions taken by bankers and their banking institutions have profound repercussions for the entire system.

In my speech today, I will outline why work on this infrastructure is still in progress: if you think of the financial system as streets and bridges, the regulatory reforms around the Basel III package have led to some repairs, some renovations and some closures. The infrastructure has become safer, but there are still several potholes and too many possibilities of a localised collapse in the system. At present, we are still in the process of finalising these reforms, of completing the reconstruction work that is very much needed.

\subsubsection{Lessons Learned, Realities Accepted}

But first, let me restate three truths that had to be learned the hard way during the crisis. And let me borrow the support of one of the leading academic figures in financial market research. About four months ago in this very room, Nobel laureate Robert Shiller presented the third edition of his book Irrational Exuberance, earlier editions of which had already 
pointed to the misguided policies of financial re-regulation in advance of the crisis long before policymakers, markets and the general public even became aware of them. ${ }^{32}$ His simple message this time was that irrational exuberance is still a defining feature of how financial markets function. Investors still follow cycles of mania and crashes, rather than rationally calculating the probabilities of all relevant scenarios - and rather than considering the negative externalities of their transactions. Full stop.

This confirms the three truths or crucial lessons to be learned realities to be accepted - and remembered. First, people are, in the majority of instances, irrational; rational calculation is severely limited internally, by our limited neurological capacities; and externally, by uncertainty in a complex world. For supervisors this implies that regulation cannot assume rational behaviour, but interconnection and herding behaviour. Negative externalities of market participants' decisions are still pervasive.

Moreover, second, these human limitations are not mitigated by market structures. If anything, blind faith in unregulated markets has made herding behaviour worse. Markets are not self-regulating entities, but socially constructed institutions that need publicly enforced rules. The third truth is that banks, supervisors and policymakers neglected these insights and failed in providing a stable financial system that serves the real economy.

So, when we discuss the consequences and further course of regulatory reform, we should always keep these simple, but rather inconvenient, truths in mind.

\subsubsection{Where We Are, and Where We Need to Go}

What helps this purpose is to remember the costs of the crisis. Combining the direct costs of stabilising the financial system with the costs of forgone production due to underutilised economic capacities, the global costs are huge. When we carry out cost-benefit analyses of regulatory measures, we should remember the enormous amount of tax money spent on bank bail-outs.

This experience and the fact that regulatory failure was one of the key causes of the financial crisis, put pressure on policymakers and supervisors to revamp the regulatory framework. And the Basel Committee on Banking Supervision, the Financial Stability Board and other standardsetting bodies have paved the way for this reform. I will come to some elements of this later, but, most importantly, the Basel Committee devised the Basel III framework with enhanced capital requirement rules, 
a leverage ratio, new liquidity regulations, new macroprudential instruments and several further elements. In the EU these rules have been translated into the Capital Requirements Regulation, CRR, and the Capital Requirements Directive IV. Moreover, in the euro area, we have created the banking union with a Single Supervisory Mechanism and a Single Resolution Mechanism.

And the reforms have actually worked. They have played a considerable part in stabilising the banking sector. Between 2008 and 2014 European banks have shrunk their balance sheets by 20 per cent and have increased their capital ratios by 5 percentage points from less than 9 per cent to around 14 per cent, where the latter has been achieved through reduced volumes of risk-weighted assets as well as increases in own funds. As a result, most balance sheets have been reduced, and refinancing has become more sustainable.

Against this backdrop, and as memory of the crisis fades, some have begun to argue that further regulatory reforms are no longer necessary, and that they are choking the only recently restarted engine of growth.

But let me be clear: all macroeconomic studies on the impact of regulatory reforms are consistent in stressing that the overall economic benefits far outweigh the costs. ${ }^{33}$

And that means that there is no way around fully implementing the reforms that have already been initiated and finalising their outstanding elements.

To summarise the current status quo, the banking sector's construction site shows that good progress has been made; the most important bridges have been renovated, rebuilt or newly constructed. Yet, several projects still lie ahead before reconstruction is complete; let us move to the, in my view, three biggest challenges facing the banking sector.

\subsubsection{Challenge 1: Manage and Supervise Banks in a Multi-Polar Regulatory Regime}

The first challenge is encapsulated by a quite technical term, namely multi-polar regulation. Andrew Haldane of the Bank of England has published an article on it. $^{34}$ Multi-polarity refers to the now multiple regulatory requirements that banks have to meet. Rather than having to meet just one capital ratio, they now will have to surpass several minimum requirements: there are, first, the improved risk-weighted capital ratio; second, two new liquidity requirements have to be met - a short-term liquidity coverage ratio as well as a longer-term maturity mismatch ratio; third, the upcoming leverage ratio; fourth, macroprudential buffers; and, last but not least, besides better capital also subordinated 
debt requirements. I could go on. But the simple point is that a multi-polar regulatory system is a reasonable approach to make banks safer and the system more stable.

Multi-polar regulation is a "third way" between overly complex measures on the one hand and very simple measures on the other. Both alternatives have failed in the past. The complex approach - in other words, Basel II - was tested in the crisis. The crisis and the rather poor performance of internal market risk models as a basis for calculating regulatory capital requirements have made sole reliance on such an approach impossible. The simple approach, on the other hand, proved to not to be entirely adequate either: the Basel I capital ratio of 1988, which was such a simple figure, was rendered useless through regulatory arbitrage. Therefore, the new framework combines the virtues of complex and simpler instruments in a multi-polar system that overcomes several of the pre-crisis shortcomings.

Which is why the Basel Committee is currently in the process of finalising the Basel III package. The new Basel framework, as agreed in 2010, marked a milestone in the regulation of banks. No sooner had it been put in place than the Basel Committee set about tackling the variability of risk-weighted assets in portfolios with essentially similar risk profiles. This variability makes it more difficult for investors to compare one bank with another. That is why the Basel Committee is currently overhauling the standardised approaches for credit, market and operational risks. It is also planning to introduce capital floors for internal models based on the standardised approaches. And, finally, we will improve the regulation of internal models so that risk sensitivity, simplicity and comparability will be enhanced.

Another much needed change to the regulatory framework for banks is a revision of the privileged treatment of sovereign bonds. This is another item currently on the agenda of the Basel Committee, given the experience of the recent sovereign debt crisis in the euro area. The Bundesbank is arguing for government bonds to be backed with a risk-appropriate amount of capital and for large exposure limits, just like those for claims on private debtors.

These reforms and the reforms that have already been finalised have led us into a world of multiple regulatory instruments. Some criticise this. Still, I believe it to be a reasonable approach, because it keeps in check the complexity that is inherent in today's risk-based regulations. Each of the new instruments will capture and limit the risks from banks with differing business models and risk profiles. The leverage ratio might not allow the detection of high-risk investment strategies, but that job will 
be performed using the risk-weighted approach. And the future floor will limit the problems that have emerged with internal models.

For banks, risk regulation becomes an even more complex optimisation problem. A bank's management has to integrate its business model with the multiple regulatory requirements. This implies a major challenge for operational processes, for risk management and, last but not least, for profit generation.

To sum up, the successful management and supervision of banks under multiple regulatory instruments is a key challenge for bankers and supervisors - and one, I might add, that needs to be combined with the challenge of rethinking a bank's strategy and business model. I will come back to this point later.

\subsubsection{Challenge 2: Ending "Too Big to Fail" - Finalising the Recovery and Resolution Framework and Making It Work in Reality}

The second challenge opens up a previously untouched layer of the banking infrastructure for reconstruction. As my colleague Andrew Bailey from the Bank of England has rightly criticised, the call for ever-higher capital provisions neglects that there are other ways to successfully protect financial stability. I refer to the rules that are designed to make banks resolvable without systemic disruption. Such reconstruction is sometimes so delicate that we might think of it as open heart surgery on the patient bank. Given the scale and sensitivity of this issue, the fact that the recovery and resolution regime has been globally agreed and will soon be implemented across Europe is an outstanding achievement. It was created to solve the problem of "too big to fail" banks and to protect taxpayers from having to bear the costs of a failure. This resolution regime is a vital step forward in acting on one of the key lessons learned from the financial crisis: the much-discussed issue of moral hazard - a problem that arose because institutions that were previously "too big to fail" could not be held accountable for their actions.

Looking ahead, there won't just be recovery and resolution plans for credit institutions: clearly defined liability cascades will be established, too, so as to ensure that the taxpayer really is last in line to foot the bill - that is to say, after shareholders and creditors have been bailed in, and then only in absolutely exceptional cases. But, to put this theoretical resolution model into practice, institutions will need to hold a certain amount of additional debt which, should the need arise, will be transformed into loss-absorbing capital. 
For global systemically important banks, this will be achieved by a standard for total loss-absorbing capacity of banks, TLAC in short, which the G20 leaders will hopefully finalise at their summit in Antalya next month. The same principle applies to the European institutions, but implementation here is based on what is known as the MREL standard, which differs in some respects from the TLAC requirement. One difference is that the minimum requirements will be set individually for each institution by the competent resolution authority.

These new standards will have a transformative impact on the market for loss-absorbing debt capital. They will introduce new instruments and will enhance standardisation of subordinated debt. In combination with new disclosure requirements, these standards will lead to transparent, attractive investment opportunities. But, at the same time, this will also lead to the pricing in of the increased probability of a bail-in - in other words, investors will demand higher risk premiums.

\subsubsection{Challenge 3: Learning to Live with Different Market Structures}

This brings me to my third challenge, namely adapting to new, different market structures. What do I mean by that? Two things: first, market structures are going to be different than before the crisis - in particular less liquid; second, in such a new environment, banks need to adapt their strategies to survive. While both trends will be monitored closely by supervisors, it is the banks and market participants that have to adapt.

Let's think first about the market environment before I come to banks and their business models. Before the financial crisis, ever-present liquidity was the touchstone of the free financial markets philosophy. The belief was that, if only demand and supply of a tradable asset were sufficiently high, you could assume perfect, frictionless markets.

But this was an illusion. Rather, the pre-crisis "liquid" market structure resulted in interconnectivity and the well-established problems of "too interconnected to fail" and "too many to fail". Moreover, this liquidity supported unsustainable trading strategies and short-termism.

Now, in the post-crisis environment, in which tougher regulation is one element, we have witnessed several new dynamics resulting from changing market structures. Particular attention has been paid to extreme, unexpected price movements that seem to have come from nowhere. The incident which received the most attention was probably the so-called flash crash of 2010. On May 6 of that year, investors were stunned when the Dow Jones plunged almost 6 per cent before recovering - and all that in 20 minutes. 
In light of such incidents some have argued that post-crisis regulation has put pressure on banks to quit activities, which led to reduced liquidity, thereby increasing the likelihood of extreme price swings. This logic provides the basis for some people's demand for a redesign of regulation.

Regulators are carefully monitoring the micro- and macroprudential implications of the reforms. However, any analysis and recommendation would have to recognise that a reduction in the trading activity of banks was a genuine intention of the post-crisis reforms. We therefore need to weigh up concerns about liquidity against reduced trading activity.

To put it bluntly: yes, markets are going to be less conducive for the generation of quick profits, but that was what was intended by the reforms - what we very much need are informed and committed investors, not short-termism. This will strengthen stability.

But that is also why banks need to adapt to the new environment. While the banking sector has been shaken, business models have not been stirred - that is, only few have been overhauled. Some stirring, however, might not hurt. And, here, it is market forces, rather than regulatory forces that come into play. What I mean is that banks must apply the acid test to their business models. Especially European banks are lagging behind in redirecting their strategies. Against the backdrop of changed market structures and in a low-interest-rate environment - which is, in all likelihood, here to stay - banks must urgently rethink their strategies to survive.

I cannot emphasise enough how pressing it is for banks to assess and adapt their business models. But let me also stress that it is not the task of supervisors to intervene in the strategic orientation of banks. We have a public mandate to put a stop to imprudent activity with the aim of securing a stable banking sector that serves the real economy. Therefore, we tax and limit negative externalities. For example, in addition to what I have already discussed, legislation and regulation of banking structural reform - also known as "ring-fencing" - is under way in the US, the UK and the EU. The regulations will ring-fence those segments of banks that deserve particular protection, in particular deposits. This is designed to internalise negative externalities and reduce moral hazard. Banks will have to accept the new public framework and construct sustainable business strategies which are compatible with it and which may restructure their group. In this regard, I fully understand the case for a large European investment bank as a response to the large US institutions - as long as it is properly regulated and not "too big to fail". Nevertheless, it is ultimately and exclusively the banks themselves that have to take these 
decisions. The role of universal banks, and whether they should be broken up, should be decided by their owners, not by the supervisors.

In terms of market-induced restructuring, supervisors prefer the banks to be stirred, but not shaken. In that sense, living with new market structures and adapting business models to ensure sustainable profitability is the third vital challenge that the banking sector is facing.

\subsubsection{Conclusion}

\section{Ladies and gentlemen}

The crisis has taught us a number of important lessons: humans, whether acting on financial markets or not, are not rational; markets are not self-regulating and do need politically mandated regulations; and supervisors, market participants and, before the crisis, policymakers failed in providing a stable financial sector.

Regulatory reform has already reversed some of the earlier mistakes, and these reforms have been highly beneficial for our economy and society. Completing these reforms will continue to be a demanding task for markets and supervisors alike. But there is no viable alternative.

In Casino Royale, when asked if he wants his vodka martini shaken or stirred, Daniel Craig (alias James Bond) replies "I don't give a damn". Well, I do. The banking sector has been shaken by the financial crisis, but not stirred by markets - at least not sufficiently. We cannot leave it to 007 to track down bad guys. Bankers and regulators both still have to do a lot to finish the reconstruction of the banking sector.

Ladies and gentlemen, that concludes my speech - thank you very much for your attention. I am looking forward to a productive discussion. And for those who missed it, the new James Bond movie was released on Monday.

$$
* * *
$$

\section{NOTES}

1. European Commission (2011), Commission wants stronger and more responsible banks in Europe. Press release, Brussels, 20 July.

2. BCBS (2011), Global systemically important banks: assessment methodology and additional loss absorbency requirement, July.

3. See FSB (2010), Framework for Strengthening Adherence to International Standards, January.

4. This is confirmed by one source from the banking industry itself: IIF (2009), Compensation in financial services: industry progress and the agenda for change, March. 
5. FSB (2009), FSF Principles for Sound Compensation Practices, April; FSB (2009), Principles for Sound Compensation Practices - Implementation Standards, September. At EU level, provisions governing remuneration were incorporated into the Capital Requirements Directive III and corresponding guidelines on compensation requirements.

6. BCBS (2011), Pillar 3 disclosure requirements for remuneration, July.

7. FSB (2011), Effective resolution of systemically important financial institutions: recommendations and timelines, Consultative Document, 19 July.

8. European Commission (2011), Commission seeks views on possible EU framework to deal with future bank failures. Press release, Brussels, 6 January 2011. The Commission announced that it intended to make the legislative proposal before the summer of 2011; it is now expected to be published this autumn.

9. Macroeconomic Assessment Group (FSB/BCBS) (2010), Final report: assessing the macroeconomic impact of the transition to stronger capital and liquidity requirements. Bank for International Settlements, Basel, December. Available at: http://www.bis.org/ publ/othp12.htm, accessed 2 April 2020.

10. Even though this definition is often attributed to Albert Einstein, he most likely never actually said it. One verified usage of this axiom is in the novel Sudden Death by US author Rita Mae Brown.

11. IMF (2016), World Economic Outlook, Update April 2016.

12. See also R. Dobbs, S. Lund, J. Woetzel and M. Mutafchieva (2015), Debt and (not much) deleveraging. McKinsey Global Institute Report, February. Available at: https://www. mckinsey.com/featured-insights/employment-and-growth/debt-and-not-much-deleveraging, accessed 2 April 2020.

13. R. Levine (2005), Finance and growth: theory and evidence. In P. Aghion and S. Durlauf (eds), Handbook of Economic Growth, Vol. 1, Amsterdam: Elsevier, pp. 865-934.

14. A. Turner (2015), Between Debt and the Devil: Money, Credit, and Fixing Global Finance, Princeton, NJ: Princeton University Press.

15. C.M. Reinhart and K.S. Rogoff (2008), This Time is Different: Eight Centuries of Financial Folly, Princeton, NJ: Princeton University Press.

16. J.L. Arcand, E. Berkes and U. Panizza (2015), Too much finance? Journal of Economic Growth, 20 (2): 105-48; European Systemic Risk Board (2014), Is Europe overbanked? Report of the Advisory Scientific Committee No. 4/June 2014.

17. S.G. Cecchetti and E. Kharroubi (2012), Reassessing the impact of finance on growth. BIS Working Paper No. 381; S.G. Cecchetti and E. Kharroubi (2015), Why does financial sector growth crowd out real economic growth? BIS Working Paper No. 490.

18. A.R. Dombret (2016), More painkillers, please? Why more finance is the wrong medicine for our growth problem. Keynote remarks delivered in Armonk, New York on 8 April 2016 at the Harvard Law School Symposium on Building the Financial System of the 21st Century: An Agenda for Europe and the US (see section 1.4 of this chapter).

19. See also R. Dobbs, S. Lund, J. Woetzel and M. Mutafchieva (2015), Debt and (not much) deleveraging. McKinsey Global Institute Report, February. Available at: https://www. mckinsey.com/featured-insights/employment-and-growth/debt-and-not-much-deleveraging, accessed 2 April 2020.

20. IMF (2016), World Economic Outlook, Update January 2016.

21. S. Lo and K. Rogoff (2015), Secular stagnation, debt overhang and other rationales for sluggish growth, six years on. BIS Working Papers No. 482.

22. European Systemic Risk Board (2014), Is Europe overbanked? Report of the Advisory Scientific Committee No. 4/June 2014.

23. B.S. Bernanke (2013), A century of U.S. central banking: goals, frameworks, accountability. Speech given at the Conference "The First 100 Years of the Federal Reserve: The Policy Record, Lessons Learned, and Prospects for the Future", on 10 July 2013.

24. M. Bordo and J. Landon-Lane (2013), Does expansionary monetary policy cause asset price booms: some historical and empirical evidence. NBER Working Paper No. 19585.

25. A. Admati and M. Hellwig (2013), The Bankers' New Clothes: What's Wrong with Banking and What to Do about It, Princeton, NJ: Princeton University Press; C.M. Reinhart and 
K.S. Rogoff (2008), This Time is Different: Eight Centuries of Financial Folly, Princeton, NJ: Princeton University Press.

26. R. Levine (2005), Finance and growth: theory and evidence. In P. Aghion and S. Durlauf (eds), Handbook of Economic Growth, Vol. 1, Amsterdam: Elsevier, pp. 865-934.

27. C.M. Reinhart and K.S. Rogoff (2008), This Time is Different: Eight Centuries of Financial Folly, Princeton, NJ: Princeton University Press.

28. J.L. Arcand, E. Berkes and U. Panizza (2015), Too much finance? Journal of Economic Growth, 20 (2): 105-48; European Systemic Risk Board (2014), Is Europe overbanked? Report of the Advisory Scientific Committee No. 4/June 2014.

29. T. Phillippon (2015), Has the US finance industry become less efficient? On the theory and measurement of financial intermediation. American Economic Review, 105 (4): 1408-38.

30. A.R. Dombret (2016), Gibt es zu viele Banken? Der Sektor nach der Finanzkrise [Are there too many banks? The sector after the financial crisis]. Lecture at the General Assembly of the Austrian Bank Science Society, Vienna.

31. For example, A. Behr and F. Heid (2011), The success of bank mergers revisited: an assessment based on a matching strategy. Journal of Empirical Finance, 18: 117-35.

32. R.J. Shiller (2015), Irrational Exuberance, Princeton, NJ: Princeton University Press.

33. A. Admati and M. Hellwig (2013), The Bankers'New Clothes: What's Wrong with Banking and What to Do about It, Princeton, NJ: Princeton University Press.

34. A.G. Haldane (2015), Multi-polar regulation. International Journal of Central Banking, 11 (3): 385-400. 